\title{
Bursting Dense Microspheres (Spherons) in Alzheimer's Disease
}

\author{
A Review of Studies (1980-1997) on Spherons and the Pathogenesis of Alzheimer's Disease
}

\author{
Paul Averback ${ }^{a}$, David Morse ${ }^{b}$ \\ and Hossein Ghanbari ${ }^{a}$ \\ ${ }^{a}$ Nymox Corporation, 5516 Nicholson Lane, \\ Suite 100A, Rockville, MD 20895, USA \\ ${ }^{b}$ Biology Department, University of \\ Montreal, 4101 Sherbrooke East, Montreal, \\ Quebec, Canada H1X 2B2
}

\begin{abstract}
This paper reviews our research studies during the past 17 years on the relationship of cerebral protein dense microspheres (DMS), termed spherons, and senile plaques (SP) in the aged human brain and in AD. Initially, correlative anatomical and pathological data suggested that spherons may evolve into SP. This led to morphometric studies which strongly supported the theory. Biochemical studies were undertaken which showed that spherons could be isolated to homogeneity from brain tissue and contained the markers associated with SP. Experiments in vitro with spherons, and with inoculation of spherons into animals, reproduced SP lesion characteristics. To test the validity of using spherons for drug screening, experimental drugs were tested, a few of which are capable of blocking the formation of spheron-induced experimental SP.
\end{abstract}

\section{INTRODUCTION}

Alzheimer's disease (AD) is presently incurable and of unknown etiology. Senile plaques (SP) in $\mathrm{AD}$ were described microscopically in the 19th century (Blocq and Marinesco, 1892) (1-3). Senile plaques are by far the largest type of abnormality found in $\mathrm{AD}$ brain, a single SP measuring up to one tenth of a millimeter in diameter (4). Moreover, in terms of optically recognizable abnormalities by routine methods roughly $90 \%$ or more of the total volume of histological abnormalities in gray matter in AD is composed of SP (1-4). The other principal optically visible abnormalities of $A D$ are histologically nonspecific, such as cell loss and neurofibrillary tangles, both of which are found in ten or more other diseases, including pediatric conditions (4-6). Senile plaques are specific for $\mathrm{AD}$ and the aged brain, and are quantitatively dominant in their significance. Although there is certainly more to AD than SP, it is difficult to argue that preventing, arresting, or otherwise decreasing SP in the brain would not be beneficial to people with AD.

Senile plaques (SP) are the characteristic and quantitatively dominant abnormality of the brain in Alzheimer's disease (AD), and SP have a number of characteristic properties which need to be addressed in any theory of their biogenesis. SP are spherical, unitary lesions which are discrete and non-confluent, and they do not enlarge past a limited unit size (1-4). A focal and high critical concentration of protein is required for SP amyloid fibril formation and SP have greatest density of amyloid internally with a gradient to the periphery (7). These and other observations imply that SP biogenesis is most consistent with a focal high concentration point origin of a discrete limited unit size rather than with an origin from a process of deposition of soluble or otherwise transported amyloid. This organization of amyloid proteins in SP is in sharp contrast to other types of non-AD amyloid disease. For example, in systemic amyloidosis, amyloid of 
circulating origin is deposited in tissues where the disease amyloid deposits are sheet-like, irregular, never spherical, and progressively become enormous, leading to gross enlargement of the affected organs, up to 5 times their normal size (8) (whereas the brain atrophies in AD (1$5)$ ).

Normal brains before old age do not contain SP, but do contain in the same cytological location in the neuropil, discrete structures of limited unit size referred to as cerebral protein dense microspheres (DMS) (9-17), termed spherons. This report presents data from several studies which show the following: Spherons are present in every human brain from early infancy, and although the average number of spherons per brain does not increase with increasing age, the individual spherons do progressively increase in size with time (from the $1-2 \mu \mathrm{m}$ diameter range at age one to the $8-10 \mu \mathrm{m}$ diameter range at age 80 ). Spherons are found in the normal brain at the same gray matter nuclear locations as SP are later found in the aged and $\mathrm{AD}$ brain. Moreover, spherons are reduced in number in $\mathrm{AD}$ and in aged brain containing SP. Spherons and SP have characteristic microspatial inter-unit distributions and their shared pattern is both (a) unique amongst optically visible elements of brain and (b) identical for SP and spherons. Species having discernible spherons correspond to species having typical SP, while species lacking visible spherons lack typical SP. Spheron size in human $\mathrm{AD}$ in different brain regions correlates with SP size in those areas. Degenerating spherons (a unique structure distinguishable from spherons and from SP and absent in normal human brain) are identified in $\mathrm{AD}$ brain. Isolation of spherons from human brain (normal and AD) and production thereby of amyloid deposits of SP size in vitro as well as in the experimental animal is demonstrated. To our knowledge, this represents the first and only instance that amyloid plaques have been produced from brain tissue derived proteins or structures (as opposed to synthetic or recombinant models). It is therefore tangible evidence for the causal relationship of spherons to SP. Isolated spherons contain molecular markers required for SP formation as determined by Western and dot blot analysis of spheron homogenates. By examining sections of in vivo inoculated spherons, and by staining in vitro samples of spherons, when individual spherons are transformed experimentally in vivo and in vitro, one spheron produces one amyloid plaque of the same size as SP in AD.

Evidence of spheron implication in SP formation satisfies 20 criteria of validity for their primary role in SP causation that are reviewed in this paper. The main observations of this spheron research have been independently verified in several other major laboratories (unpublished data). Spherons are a logical target for chemical agents which can block SP and amyloid formation in $\mathrm{AD}$. A few experimental drugs and compounds have been found to be capable of preventing the production of experimental SP from spherons.

\section{MATERIALS AND METHODS}

\section{Optical Microscopy of Spherons by Routine Histology in Paraffin Sections}

One hundred and fifty-six cases of normal brains, neurological diseases and $\mathrm{AD}$ were studied. Postmortem brains removed within 24 hours of death were immersion fixed in $10 \%$ formalin, cut, and blocks were embedded in paraffin. Blocks were made from all areas of cerebral cortex, hippocampus, thalamus, hypothalamus, striatum, three levels of brainstem, and other areas depending upon the gross findings. Sections at $5-10 \mu$ thickness were stained routinely by hematoxylin-eosin and in certain instances by a variety of stains (Table 1).

\section{Electron Microscopy}

Samples of postmortem brain from normal patients $(N=10)$ and from $\operatorname{AD}(N=10)$ were fixed in glutaraldehyde, embedded in Epon resin, sectioned on an ultramicrotome, stained with uranyl acetate and lead citrate, and viewed by transmission electron microscopy (TEM). 
Table 1

Histological staining of spherons

\begin{tabular}{ll}
\hline Stain & Reaction \\
\hline Feulgen & very pale green \\
Luxol fast blue & very pale green/blue \\
Von Kossa & light pink \\
PAS & unstained \\
PAS with diastase & unstained \\
Alcian blue & unstained \\
Heidenhain & unstained \\
Holzer & very pale blue \\
Cresyl violet & unstained \\
Sudan black & unstained \\
Sudan III and IV & unstained \\
Prussian Blue & unstained \\
Eosin & bright red \\
Toluidine blue & unstained \\
Polarized light & no effect \\
Gram & unstained \\
Van Gieson & unstained \\
Methyl green pyronine & unstained \\
Cresyl blue for platelets & light green \\
Lendrum's phloxine & red \\
tartrazine & \\
Best's carmine & pale pink-brown \\
Grocott's silver & unstained \\
Diaminobenzidine & unstained \\
\hline
\end{tabular}

\section{Frequency Studies (Spherons or SP per Cubic Millimeter) in Paraffin Sections}

Patient data are summarized in Tables $2 \mathrm{~A}$ and 2B. Spherons and SP were counted in paraffin sections of temporal neocortex stained by hematoxylin-eosin (for spherons) and Bodian (for SP). Counts were made by eye, by two individuals, based on all optically visible structures found in 40 consecutive randomly selected (stage movement from field to field with the microscope out of focus) microscopic fields at X250 magnification. Although the sections were prepared under similar conditions, some degree of error due to microtome variation (at the same setting) in section thickness is unavoidable. The counts are expressed as spherons or SP per cubic millimeter of processed tissue, arrived at by field area multiplied by section thickness corrected for truncation. The values do not correspond to frequency per unit fresh volume (the latter would require corrections for shrinkage during fixation and processing).

\section{Measurements of Spheron and SP Volume}

Sections of paraffin embedded formalin fixed postmortem samples of temporal neocortex and hippocampus were made from tissues obtained at autopsy from 60 normal controls and 12 cases of AD (summarized in Table 3). Slides were stained with eosin and Bodian stains. Diameters of individual spherons (Figure 1) and individual SP (Figure 2) $\quad(N=50$ for each) were consecutively measured, by two individuals, by optical micrometer in cerebral cortex and in hippocampus. These values were used to calculate the volume of a sphere $\left(4 / 3 \pi r^{3}\right)$ and were compared by Chi-square testing. These section-derived calculations consistently underestimate true volume (due to non-central sections) but are valid for the intended purposes of comparison.

\section{Microspatial Distribution of Spherons, SP, and Other Structures}

Twenty normal controls (12 young controls mean age $25.7 ; 8$ elderly controls mean age 73.9 ) and 12 cases of $\mathrm{AD}$ (mean age 74.3) were studied. Blocks and sections of postmortem temporal neocortex were prepared as above and stained with hematoxylin-eosin, Bodian, and Bielschowsky stains. Sections were made at $6 \mu$ thickness, and although the sections were prepared under similar conditions, some degree of error due to microtome variation in section thickness was unavoidable. Section thickness variation does not however impact the morphometric tools of this study. The basis for identification of the structures in the study was according to light microscopic criteria (spherons by eosin staining, SP by Bodian silver stained sections). SP were also compared in two cases with Bielschowsky stained sections as a control. Structures were assessed in the light microscope at X250 magnification. For consecutive fields the stage was moved by hand with the field out of focus. A calibrated micrometer (140 units) was used to make planar inter-structure distance measurements. 
Table 2A

Summary of mean values of number per unit volume of spherons and SP in cerebral cortex

\begin{tabular}{llll}
\hline Parameters & AD & $\begin{array}{l}\text { Young normal } \\
\text { controls }\end{array}$ & Old normal controls \\
\hline $\mathrm{N}$ & 16 & 20 & 20 \\
Mean Age (S.D.) & $74(12.3)$ & $24.5(3.6)$ & 70.1 \\
Mean Brain Weight (S.D.) & $1241(127)$ & $1323(167)$ & $1305(151)$ \\
Spherons $/ \mathrm{mm}^{3}$ (S.D.) & $222(103)$ & $581(407)$ & $518(392)$ \\
$\mathrm{SP} / \mathrm{mm}^{3}$ (S.D.) & $352(193)$ & 0 & 0 \\
Spherons + SP $/ \mathrm{mm}^{3}$ (S.D.) & $574(222)$ & $581(407)$ & $518(150)$ \\
\hline
\end{tabular}

Table 2B

Number of spherons and SP in AD individuals

\begin{tabular}{|c|c|c|c|c|c|c|c|}
\hline Number & Age & Sex & Cause of death & $\begin{array}{l}\text { Brain } \\
\text { weight }\end{array}$ & Spherons $/ \mathrm{mm}^{3}$ & $\mathrm{SP} / \mathrm{mm}^{3}$ & $\begin{array}{l}\text { Spheron+SP } \\
\text { total/mm }{ }^{3}\end{array}$ \\
\hline 1 & 81 & $\mathrm{M}$ & Cardiac arrhythmia & 1370 & 236 & 288 & 524 \\
\hline 2 & 87 & $\mathrm{~F}$ & Cardiac arrest & 1050 & 129 & 766 & 895 \\
\hline 3 & 66 & $\mathrm{M}$ & Lobar pneumonia & 1320 & 425 & 541 & 966 \\
\hline 4 & 62 & $\mathrm{M}$ & Bronchopneumonia & 1325 & 250 & 164 & 414 \\
\hline 5 & 57 & $\mathrm{~F}$ & Bronchopneumonia & 1220 & 100 & 283 & 383 \\
\hline 6 & 92 & M & $\begin{array}{l}\text { Ruptured abdominal } \\
\text { aortic aneurysm }\end{array}$ & 1185 & 225 & 167 & 392 \\
\hline 7 & 52 & $\mathrm{M}$ & Aspiration & - & 100 & 448 & 548 \\
\hline 8 & 90 & $\mathrm{~F}$ & Bronchopneumonia & 1085 & 300 & 250 & 550 \\
\hline 9 & 76 & M & $\begin{array}{l}\text { No single anatomical } \\
\text { cause }\end{array}$ & 1480 & 258 & 398 & 656 \\
\hline 10 & 60 & $\mathrm{~F}$ & $\begin{array}{l}\text { No single anatomical } \\
\text { cause }\end{array}$ & 1210 & 325 & 158 & 483 \\
\hline 11 & 73 & $\mathrm{M}$ & Bronchopneumonia & 1150 & 364 & 376 & 740 \\
\hline 12 & 89 & $\mathrm{~F}$ & Bronchopneumonia & 1060 & 86 & 91 & 177 \\
\hline 13 & 75 & M & Bronchopneumonia & 1301 & 236 & 408 & 644 \\
\hline 14 & 75 & $\mathrm{M}$ & Bronchopneumonia & 1340 & 173 & 182 & 355 \\
\hline 15 & 80 & M & $\begin{array}{l}\text { Chronic myelogenous } \\
\text { leukemia/respitatory } \\
\text { failure }\end{array}$ & 1280 & 86 & 442 & 528 \\
\hline 16 & 69 & $\mathrm{M}$ & unavailable & N/A & 258 & 676 & 934 \\
\hline
\end{tabular}

Table 3

Summary of individuals for size measurement data

\begin{tabular}{llcr}
\hline & $N$ & Mean age & S.D. \\
\hline 1. Normal age 1-10 & 10 & 4.4 & 1.2 \\
2. Normal age 20-40 & 25 & 29.2 & 3.5 \\
3. Normal age 65-90 & 25 & 76.1 & 8.2 \\
4. Alzheimer's disease & 12 & 74.3 & 15.6 \\
\hline
\end{tabular}




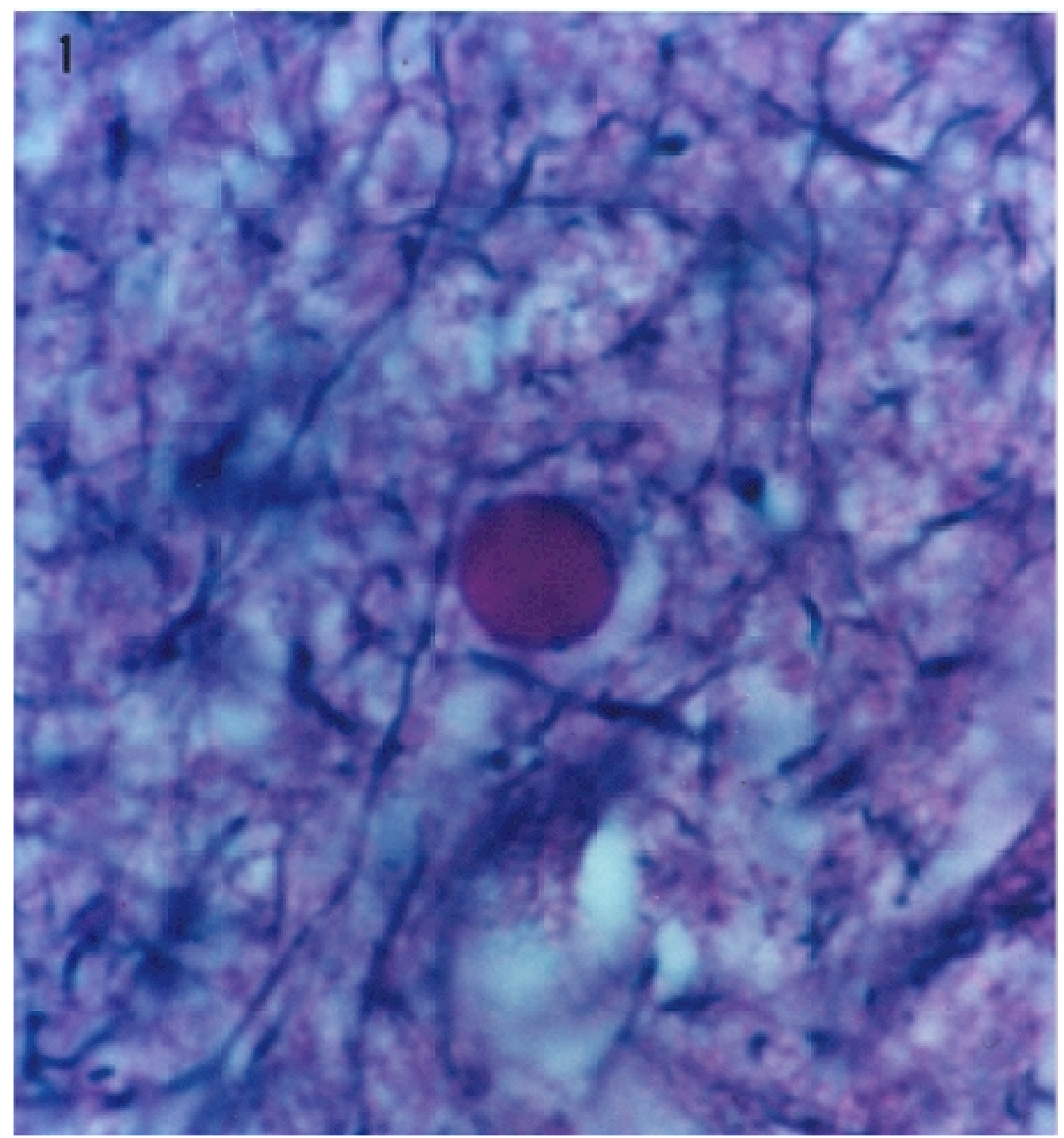

Fig. 1. Typical light microscopic appearance of spheron. Formalin fixed paraffin embedded section of normal human cerebral cortex stained with Bodian and eosin, viewed under oil immersion, total magnification X 4,000. Spherons are solitary structures in the neuropil which are unassociated with neuronal perikarya, are brightly eosinophilic, highly refractile and perfectly spherical. With the light microscope using these methods the intradendritic location cannot be shown. 

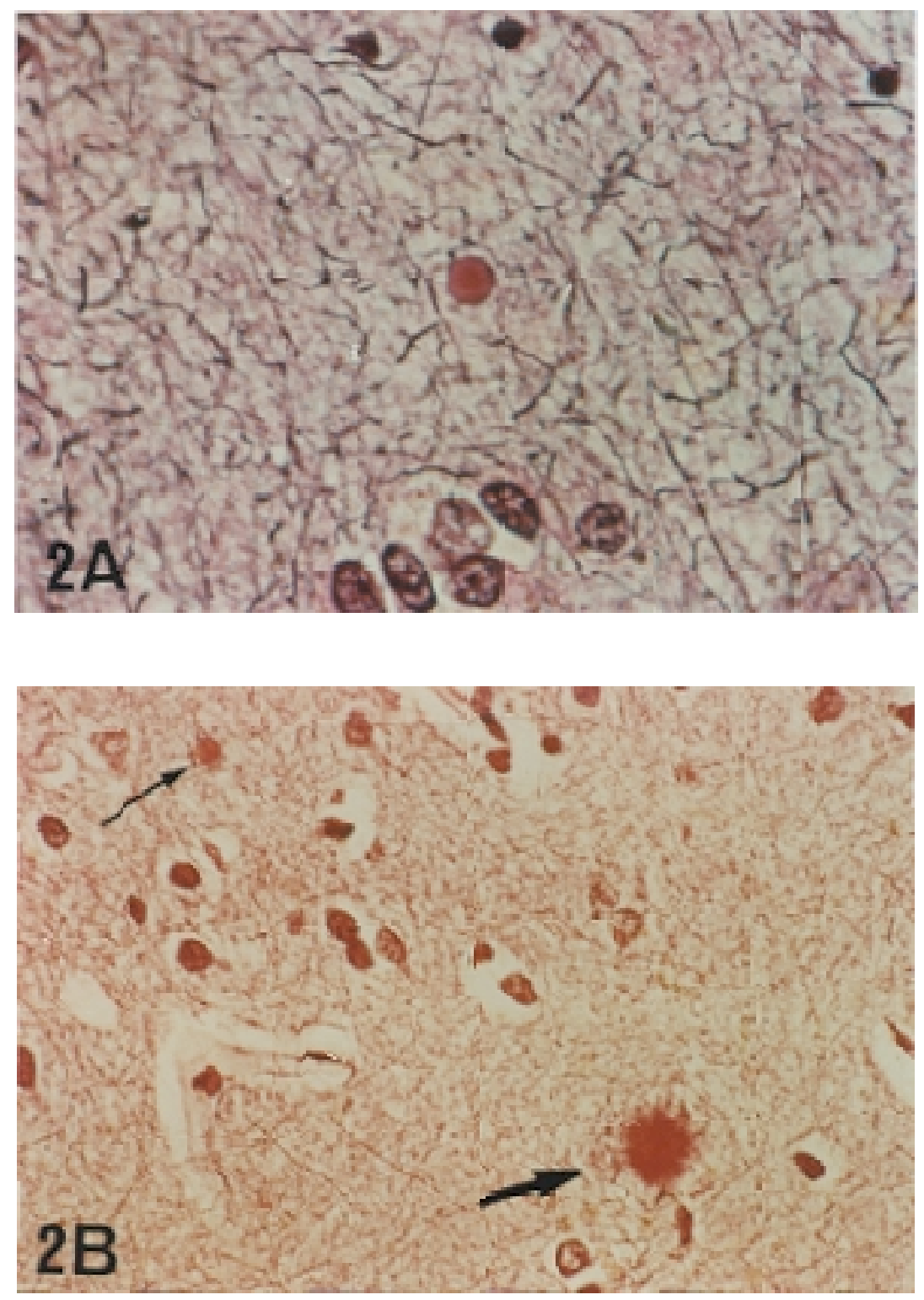

Fig. 2. Illustration of SP and spheron in AD brain. (A) Formalin fixed paraffin embedded section of AD cerebral cortex with spheron in center of field stained with Bodian and eosin, X 1,000. (B) Arrows show spheron (top, small arrow) and SP (bottom, large arrow). Both SP and spherons are solitary spherical structures, found in the neuropil unassociated with perikarya. X 750. The top figure illustrates larger appearing spheron likely due to more central section.

Structure count per field was made by eye by two individuals. These particular measurements for individual spherons within a section of intact brain are not reliably amenable to image analysis automation.

The following structures were compared: 1 . neurons $(\mathrm{N}) ; 2$. blood vessels $(\mathrm{V}) ; 3$. non- neuronal cells $(\mathrm{G}) ;$ 4. polyglucosan bodies (corpora amylacea) (CA); 5. SP; and 6. spherons. For each of the above the following parameters (18-23) were calculated: (1) $\lambda_{\mathrm{T}}$, the particle density per unit volume of tissue; (2) $d_{\mathrm{e}}$, the expected mean minimal planar inter-particle distance on the basis of a Poisson process, 
calculated as $\lambda_{\mathrm{T}}{ }^{-1 / 2} / 2 ;(3) d_{0}$, the observed mean minimal planar inter-particle distance; (4) $D$, the ratio $d_{\mathrm{o}} / d_{\mathrm{e}}$; (5) $D_{2}$, a function of $d_{i}$ as defined in 2 and 3, where $D_{2}=\Pi \lambda_{\mathrm{T}} \sum_{i=1}^{n}\left(d_{i}\right)^{2} / n ;$ (6) $\lambda q$, the mean quadrat density of particles in random fields; (7) $P(X=x)$, the expected Poisson probability quadrat count where $P=\mathrm{e}^{-\lambda q} \lambda^{x} q / x$ !, $x=0,1,2, \ldots$; (8) $N_{x}$, the field count with quadrant density $x$, where $x=0,1,2, \ldots$.

\section{Studies of Spherons in Other Species of Animals}

Hematoxylin-eosin stained paraffin sections of cerebral cortex were examined from a variety of non-human species, from postmortem material as available with permission from the Veterinary School of the University of Montreal. Age and conditions of fixation and numbers of sections were not controlled and quantitative, histochemical and topographic aspects were not addressed due to the limitations of the material. Samples were examined from monkeys, dogs, cats, cows, pigs, racoons, deer, goats, sheep, horses, bears, chickens, birds, guinea pigs, squirrels, rabbits, mice and rats. In most of the preceding, multiple different breeds were studied.

\section{Isolation of Spherons}

At each stage of the isolation procedures, fractions were examined by light microscopy (of eosin stained fractions) or TEM if necessary. Spherons were prepared from whole brains, removed from the skull post-mortem by standard post-mortem techniques, and dissected in a cold room to remove the internal capsules, corona radiata, centra semi-ovale, cerebellum, lepto and pachymeninges, arachnoid granulations, choroid plexi and large blood vessels. The remaining mass of brain tissue (typically about $200 \mathrm{~g}$ ) was homogenized in a Waring blender in $400 \mathrm{ml} 0.5$ M Tris-buffer ( $\mathrm{pH} 7.5)$ and centrifuged at $1000 \times g$ for 10 minutes. The pellet was resuspended in $100 \mathrm{ml} 0.5 \mathrm{M}$ Tris- $\mathrm{HCl}(\mathrm{pH} \mathrm{7.5)}$ and layered across a sucrose gradient $(10 \mathrm{~mL}$ each $45 \%, 52 \%$ and $62 \%$ sucrose in tris buffer) in $1 \mathrm{ml}$ aliquots.
The tubes were centrifuged at $30,000 \times g$ for 30 minutes at $4{ }^{\circ} \mathrm{C}$ and the material at the $52-62 \%$ interface isolated. This fraction contains spherons as confirmed by microscopic examination of the fractions. The fractions from all separate tubes were pooled, diluted with 10 volumes of $0.5 \mathrm{M}$ Tris- $\mathrm{HCl}(\mathrm{pH}$ 7.5) and centrifuged at $3,000 \times g$ for 10 minutes. The pellet was resuspended in $10 \mathrm{ml} 0.5 \mathrm{M}$ Tris buffer and recentrifuged as above. The final spheron preparation was resuspended in 1-2 $\mathrm{ml}$ sterile $0.5 \mathrm{M}$ Tris- $\mathrm{HCl}$ and verified by microscopy before being stored frozen at $-20^{\circ} \mathrm{C}$. For light microscopy, eosin staining was performed in microcentrifuge tubes, and the excess stain removed by centrifugation prior to observation of the samples. For TEM, the samples were embedded in a $1 \%$ agar block prior to fixation, sectioning and staining.

\section{Gel Electrophoresis of Spheron Preparations}

Spherons preparations were analyzed by polyacrylamide gel electrophoresis (24) by solubilization in standard sodium dodecyl sulfate (SDS) sample buffer containing 1\% SDS and 1.4 $\mathrm{M} \beta$-mercaptoethanol. The gels were stained by coomassie blue and silver.

\section{Western Blot and Dot Blot Analysis of Spheron Preparations}

For immunoblotting, gels were electrophoretically transferred to nitrocellulose (26) and the transfers checked by staining with Ponceau S. Antibodies used were directed either against amyloid precursor protein (APP, Boehringer Mannheim) or A- $\beta$ 1-40 (Sigma). Reaction was visualized with a peroxidase labeled secondary antibody and a chemiluminescent detection system (Boehringer). Dot blots were made from sonicated and mechanically disrupted spherons placed directly on nitrocellulose, which were then immunostained as above. Mechanical disruption of spherons is described below (Experimental production of amyloid in vitro from purified spherons). 


\section{Immunohistochemical Staining of Amyloid Antigens in Transformed Spherons}

Antibodies against A- $\beta$ and APP as above were used by conventional methods to stain spheron material in paraffin embedded sections of experimental spheron inoculation sites, and in in vitro preparations of disrupted spherons. In different instances, sections were preincubated with nothing or with $0.1 \%$ trypsin, $0.1 \%$ pepsin, or $70 \%$ formic acid, were incubated with the primary antibody for 1 hour to overnight, at $4^{\circ} \mathrm{C}$ or $37^{\circ} \mathrm{C}$, and were incubated with secondary antibodies conjugated either to horseradish peroxidase or alkaline phosphatase.

\section{Experimental Production of Amyloid In Vivo from Purified Spherons}

All injections used Wistar male rats between 2-3 months of age. The animals were anesthetized by ether inhalation and spheron injections were made using sterile technique. For injection into brain tissue, two $50 \mu 1$ samples of the spheron preparations in Tris buffer (containing roughly $10^{4}$ spherons each) were injected by tangential injections through a 22 gauge needle for a distance of several $\mathrm{mm}$ into the cerebral cortex at two or more different sites through a small hole bored in the skull of groups of six animals. Larger volumes of the spheron preparations $(100 \mu l)$ were injected subcutaneously into the backs of groups of six animals (one injection at each of two sites per animal). At various times post-injection $(1,4$, 12,24 or 48 hours and 1 or 4 weeks), the animals were sacrificed by ether and $\mathrm{CO}_{2}$ insufflations. Tissue containing the injection site was excised with the aid of dissecting microscope. Tissue blocks were immersion fixed in formalin, embedded and sectioned and stained with hematoxylin-eosin and Congo Red using standard techniques. Control groups of two animals each were injected as above at the same time intervals in brain and in skin with $50 \mu \mathrm{L}$ (brain) and 100 $\mu \mathrm{L}$ (skin) of: 1 . saline only 2 . homogenized crude human cerebral neocortical tissue and 3 . homogenized crude human cerebellum. Injection experiments were observed under code by two observers.

\section{Experimental Production of Amyloid In Vitro from Purified Spherons}

Samples of purified spheron preparations $(50$ $100 \mu \mathrm{L}$ ) were placed on glass microscope slides and allowed to dry at room temperature. A firm stainless steel spatula was mechanically moved in a forceful scraping motion over the spheron material for five minutes. The disrupted material was then rehydrated in $30 \mu \mathrm{L}$ of $0.5 \mathrm{M}$ Tris- $\mathrm{HCl}$ buffer ( $\mathrm{pH}$ 7.5) buffer and allowed to dry at room temperature. The slide was then stained with Congo red and examined by microscopy.

\section{Initial Experimental Drug Studies for the Modification of Spheron Transformation into SP Amyloid}

Spheron preparations (containing roughly $10^{4}$ spherons in $50 \mu \mathrm{L}$ ) were incubated with $100 \mu \mathrm{L}$ of solution $(100 \mu \mathrm{M})$ of compounds to be screened for 30 minutes in a microfuge tube at room temperature and then injected subcutaneously or intracerebrally into rats as described above. Animals were sacrificed at various time intervals and samples were removed and processed as described above.

\section{RESULTS}

\section{Optical Microscopy of Spherons in Paraffin Sections}

Spherons are brightly eosinophilic homogeneously dense and refractile spherical solitary bodies in the neuropil (Figures 1,2,3). They have not been seen (on section) adjacent to neuronal perikarya, nor have they been clearly identified within perikarya. A hint of silver stain can perhaps be discerned at the spheron periphery occasionally when counterstained, for example in a Bodian and eosin preparation. The routine staining reactions are summarized in Table 1. Spherons are present in all brains but the 
cytological location, intradendritic or otherwise, cannot be discerned in the light microscope by these methods. Spherons at the optical level were not seen in newborns but are regularly present by the age of one year. The optical data does not of course rule out the possibility that spherons may be present at the ultrastructural level from as early as in utero. Spherons on average progressively increase in size throughout life (see Size correlation of spherons and SP, below, Figures $5 \mathrm{~A}$ and $5 \mathrm{~B}$, and Tables $4 \mathrm{~A}$ and $4 \mathrm{~B}$ ). They are readily found in all gray matter areas with the exception of the cerebellum. Spherons are absent from white matter. They have not been found in the peripheral nervous system. Our anatomical findings have subsequently been verified by others $(27,28)$.

\section{Degenerating Dense Microspheres (DDMS) in AD}

In $\mathrm{AD}$ brains, eosinophilic structures could be observed which are distinguishable from spherons, and which are located where spherons normally are found (Figure 3, bottom). The localization (identical to spherons) was solitary in the neuropil, unassociated with any perikarya, in all gray matter nuclei with the exception of the cerebellum. The preponderance (not quantified by counting studies) appeared to be in frontal and temporal neocortex, hippocampus, and subcortical nuclei; with fewer examples in occipital and parietal cortex, and with rare examples seen in brainstem and spinal cord.

The DDMS measure 10-25 microns in diameter and are a variety of shapes, from slightly eccentric to pear shaped, to highly irregular or fractured in appearance (Figure 3). The DDMS are not Congophilic or birefringent and have little or no associated silver positive neuritic elements which clearly distinguishes them from SP. The surrounding neuropil is optically normal. The DDMS is periodic acid Schiff negative. Although some examples may stain for A- $\beta$, in the limited number of examples studied, staining for A- $\beta$ or APP has appeared to be negative.
DDMS were not found in normal brains. In $\mathrm{AD}$ brain the frequency per cubic millimeter was variable (estimated at 10-100 per cubic millimeter). DDMS are readily observed in brain tissue containing higher number of SP per cubic millimeter.

\section{Electron Microscopy of Spherons}

Spherons are shown to be homogeneously election-dense intraneuronal structures (Figure 7C). Adjacent synaptic elements in the cytoplasmic process identify the latter as neuronal and suggest that it is dendritic. In other examples the type of cell process cannot be discerned. The spheron appears to have a poorly resolved outer ribbon which could be a spheron membrane, or it may be an outer spheron layer artefactually separated from the spheron. This ribbon is not well seen in TEM of purified spherons. Mitochondria are often found near the spheron, although not in any abundance (one or two per thin section). Our observations have been verified by others $(27,28)$.

Electron microscopy of examples of DDMS revealed electron dense structures with surface distortions that correlated with the optical appearance. No fibrillar amyloid material was discernible. The surrounding neuropil was unchanged in comparison to control normal brain postmortem artifacts. Electron microscopy of DDMS confirms that DDMS are distinct structures and are readily distinguishable from spherons and from SP.

\section{Studies of the Number per Cubic Millimeter of Spherons and SP}

The number of spherons in normal brain is stable across age groups (Table 2). In $\mathrm{AD}$, mean spheron number is reduced $57 \%$ from agematched normal controls (AD: $222 / \mathrm{mm}^{3}$; normal controls: $518 / \mathrm{mm}^{3}$ ). The sum of SP number plus spheron number, however, remains constant (Table 2) (Figure 4). The SP number range in our data is comparable to the published ranges of other groups when corrected for section thickness (30-34). 

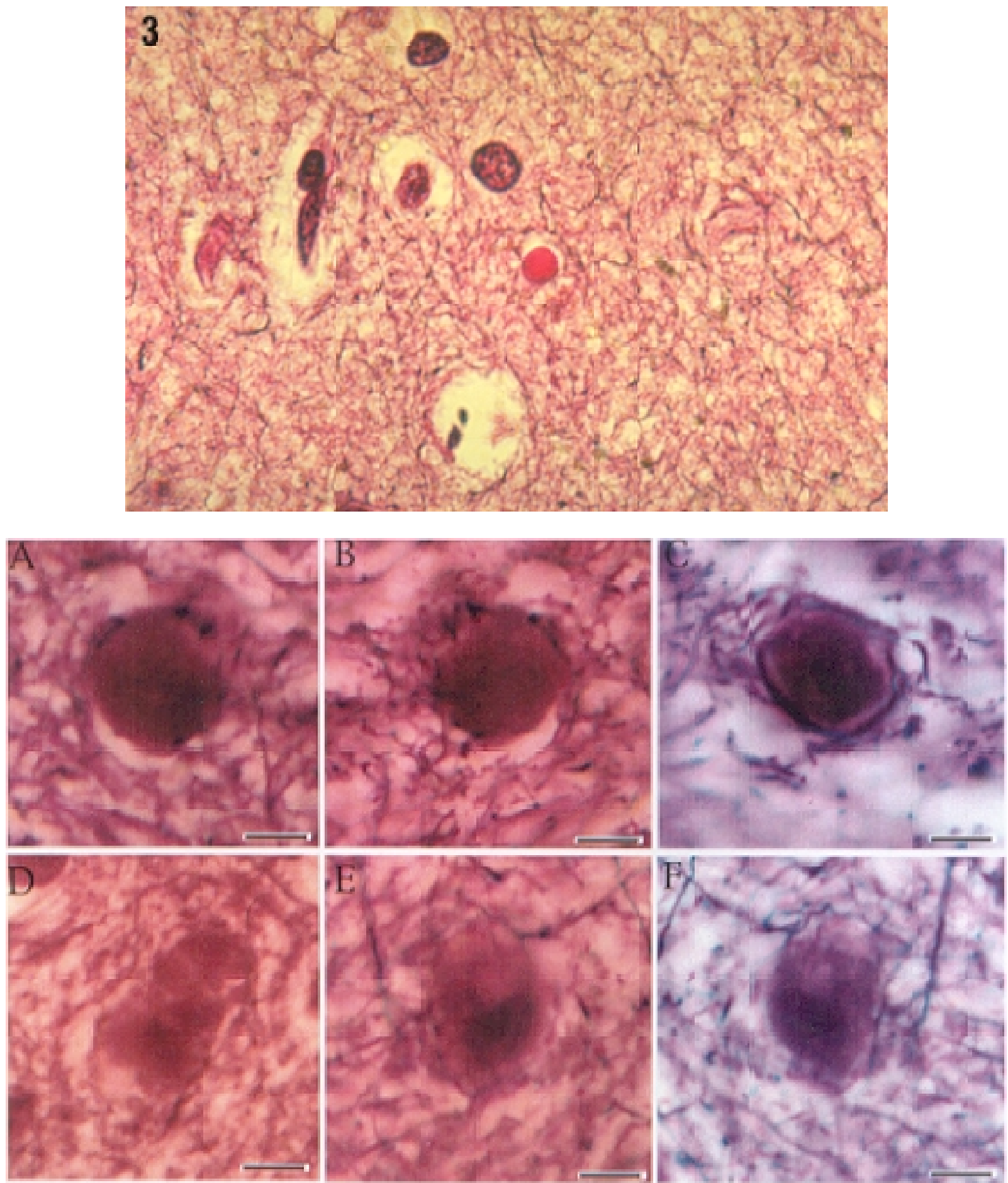

Fig. 3. Degenerating spherons (DDMS) in AD brain. Top figure illustrates normal spheron in normal brain, X 1200 . Lower figures are of formalin fixed paraffin embedded sections of AD cerebral cortex stained with Bodian and eosin, viewed under oil immersion, total magnification X 2,200. Examples of DDMS demonstrate normal surrounding neuropil (silver negative) distinguishing them from typical SP. DDMS demonstrate eccentricity, inhomogeneity, and other deviations from the perfectly homogeneous normal spherical spheron. Bar $=5 \mu$ 
Table 4A

Size of spherons $\left(\mu^{3}\right)^{a}$

\begin{tabular}{lccc}
\hline Age range & $1-10$ & $20-38$ & $65-90$ \\
Number of Subjects & 10 & 25 & 25 \\
\hline Mean spheron volume, temporal & 7.2 & 12.4 & 28.5 \\
neocortex & 13.9 & 27.4 & 65.5 \\
Mean spheron volume, hippocampus & 1.91 & 2.21 & 2.30 \\
Ratio of hippocampal / cortical spheron & volume & & $\mu$ \\
\hline
\end{tabular}

${ }^{a}$ Based on section derived calculations which underestimates true volume.

Table 4B

Size of SP ${ }^{a}$

\begin{tabular}{lcc}
\hline & Mean diameter $(\mu \mathrm{m})$ & Mean volume $\left(\mu^{3}\right)$ \\
\hline Temporal neocortex & 34.1 & 20,770 \\
Hippocampus & 61.8 & 123,634 \\
\hline
\end{tabular}

${ }^{a}$ based on section derived calculations which underestimates true volume.

\section{Size Correlation of Spherons and SP}

Data are summarized in Tables $4 \mathrm{~A}$ and $4 \mathrm{~B}$ and Figures $5 \mathrm{~A}$ and $5 \mathrm{~B}$. Individual spherons increase in size throughout life (Figure 5A). Hippocampal spherons are 1.91-2.30 times the volume of temporal neocortical spherons at each of the age intervals studied, and in particular at the 70-80 age group (when SP are more prevalent). The same relationship exists for SP (Chi-square $p<0.001)$ which are 1.81 times the diameter or 5.93 times the volume in hippocampus when compared to temporal neocortex (Figure 5B). The ratio of SP volumes (5.93) is similar to the square of the ratio of the spheron volumes (5.29 at age 70-80). These diameter measurements and volume calculations were based upon sectioned spheres in paraffin sections, and therefore the values are consistently under-estimated but the comparisons are valid. As expected, whole spherons in extracted samples appear on average larger than in sections. Our SP measurement data are similar to other subsequent studies where SP have been measured in these areas (35).

\section{Microspatial Distribution of Spherons and SP}

Results are tabulated in Tables $5 \mathrm{~A}$ to $5 \mathrm{C}$ and summarized in Table 6. The mean $\mathrm{D}$ value for spherons in neurologically normal young adults (age range 20 to 38 ) was 0.931 , compared to 0.970 in the non-demented older control (age range 55-88) group, and 0.915 for $\mathrm{SP}$ in the AD group. Comparable values for $\mathrm{N}, \mathrm{V}, \mathrm{G}$, and $\mathrm{CA}$ ranged from 0.14 to 0.52 . The mean Chi-square for quadrat count estimates for spherons in young controls was 4.80 , for spherons in older controls was 3.71 and for SP in the AD group was 3.01, no individual instance reaching statistical significance. D values vary over the interval from zero to 2.15 with 0 indicating a perfect cluster and 2.15 indicating maximal orderly dispersal and 1.0 indicating random distribution. The CA values (0.14-0.52) reflect relative clustering in comparison to SP and spherons. The D values for N, G, and V (1.61-2.15) reflect more regular spacing. The spheron and SP values are not significantly different and are the only elements with this degree of randomness at that level of $\lambda_{\mathrm{T}}$. 


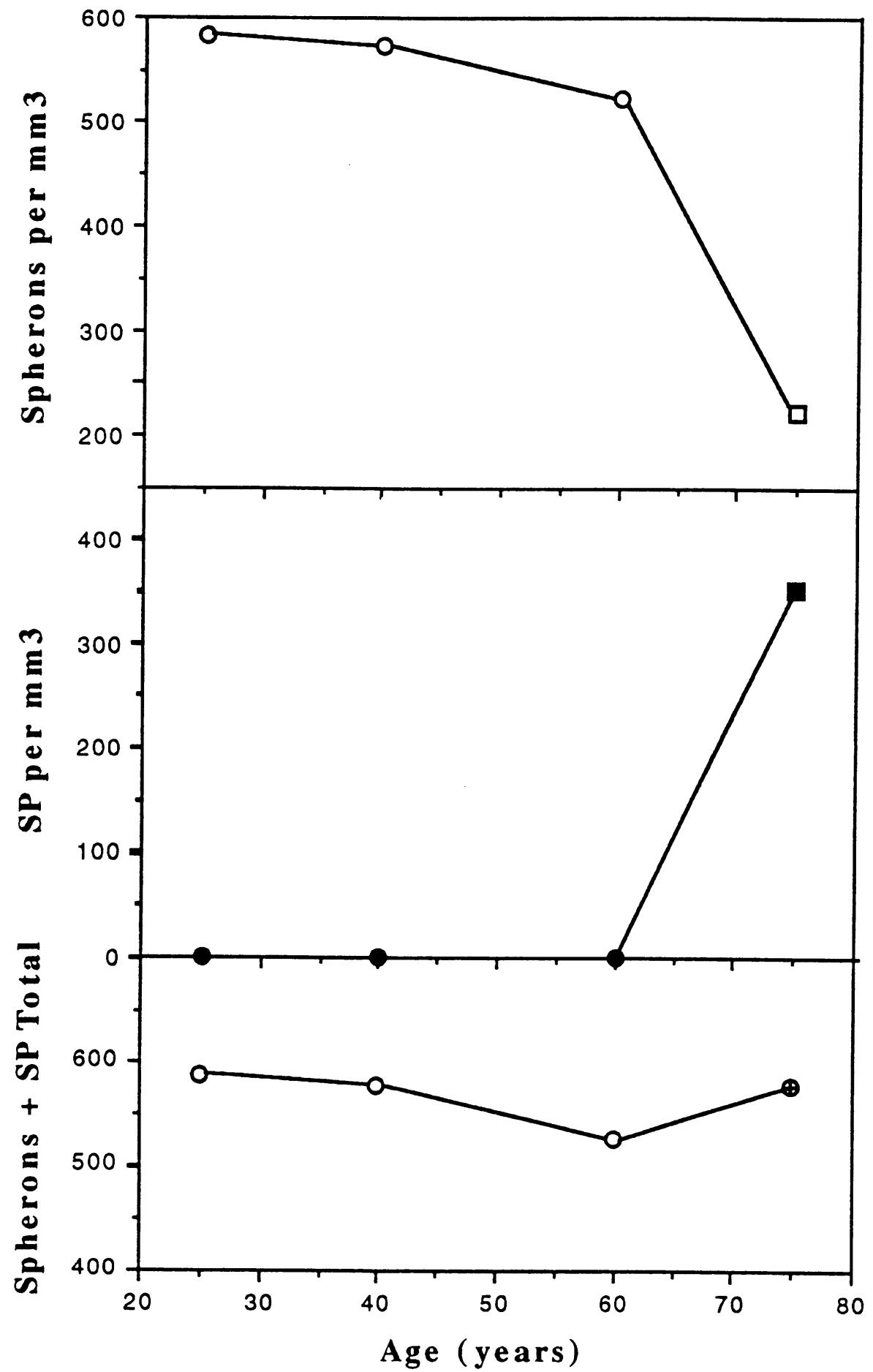

Fig. 4. Graph illustrating the relationship $\mathrm{Sph}+\mathrm{SP}=\mathrm{K}$. On average, the number of spherons is reduced in $\mathrm{AD}$ proportionately to the number of SP which appear in AD. Top shows spheron frequency per unit volume cortex at different ages in normal brain (open circles) and AD (open square). Middle shows SP frequency per unit volume cortex at different ages in normal brain (solid circles) and $\mathrm{AD}$ (solid square). Bottom shows (spherons plus SP) at same ages. The (spherons plus SP) total remains statistically constant. 


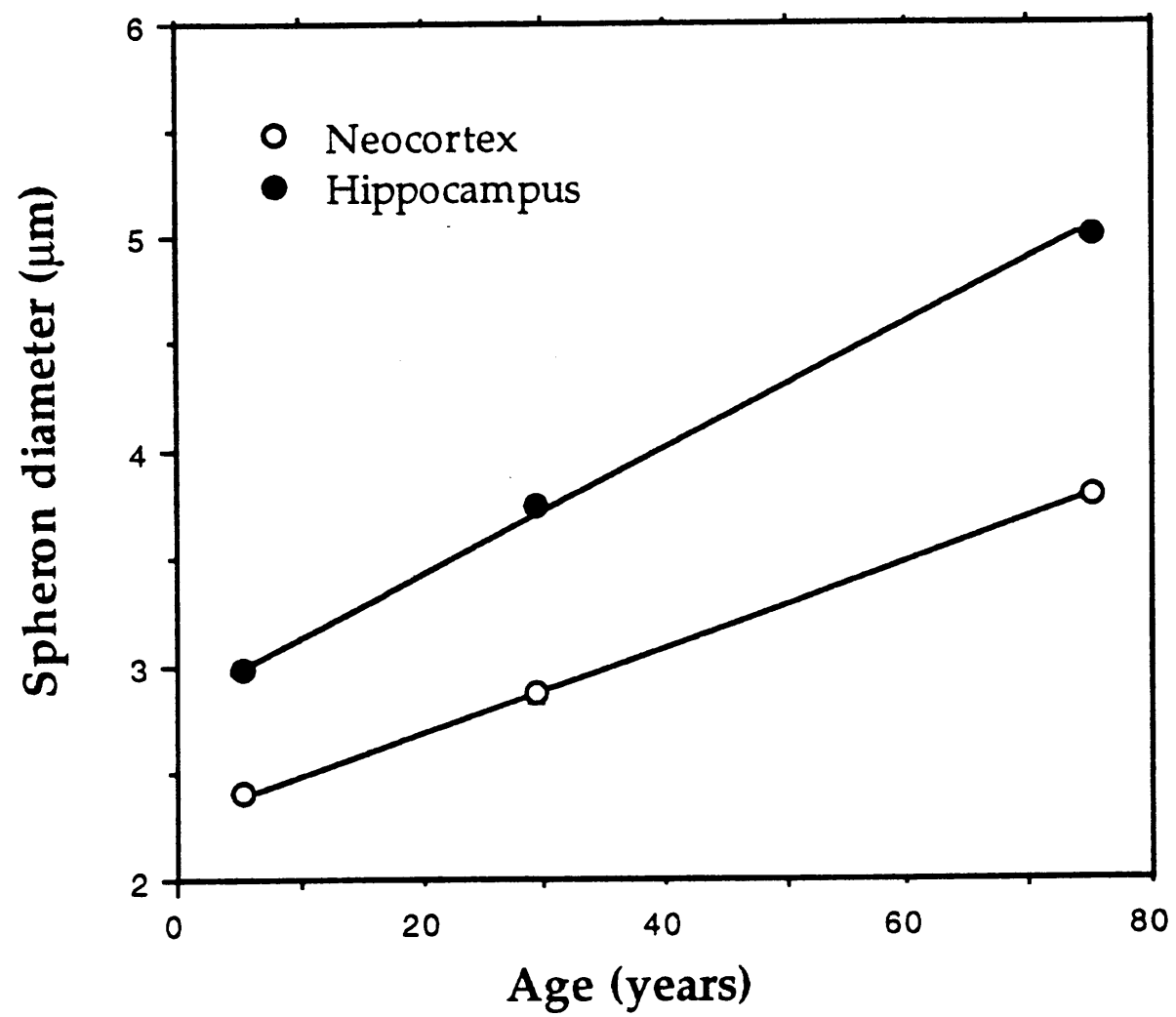

Fig. 5A. Individual spherons increase in size throughout life. Mean spheron size is plotted against age in hippocampus and cortex in normal brain. Spherons progressively increase in size with age. Mean true diameter is underestimated by this method of measurement (in sections), but is valid for comparison purposes.

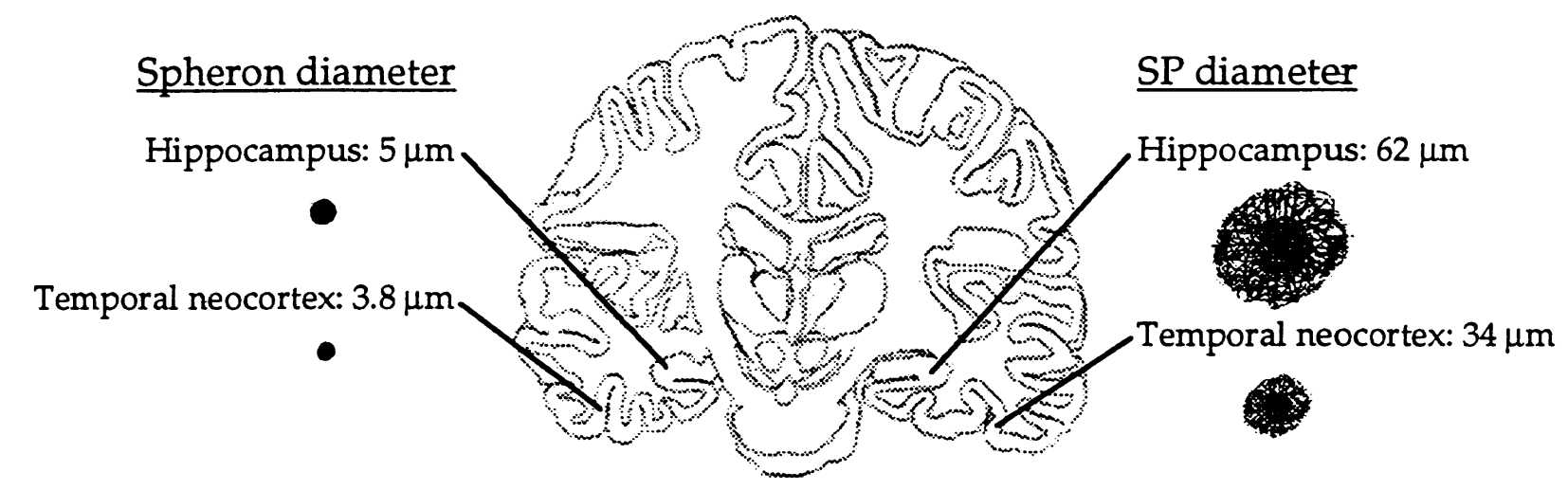

Fig. 5B. Schematic representation of size gradient of SP and spherons in hippocampus and in temporal neocortex. The two entities (SP and spherons) both have non-overlapping distributions when compared in these two regions. There is a significant (Chi-square $p<0.001)$ relationship between spheron size and SP size. The ratio of SP volume (hippocampal divided by cortical) is comparable to the square of the ratio of the spheron volumes (hippocampal divided by cortical). 


\section{Clustered}

$D<1$

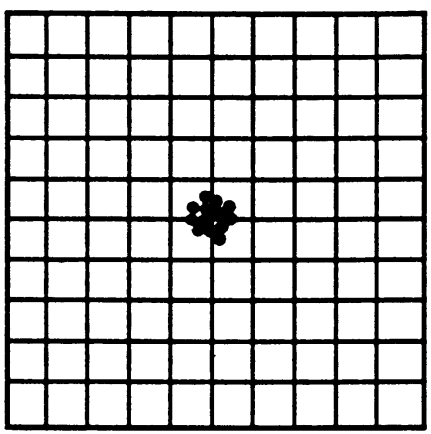

Polyglucosan bodies $\mathrm{D}=0.33 \pm 0.19(\mathrm{~N}=10)$
Random

$\mathrm{D}=1$

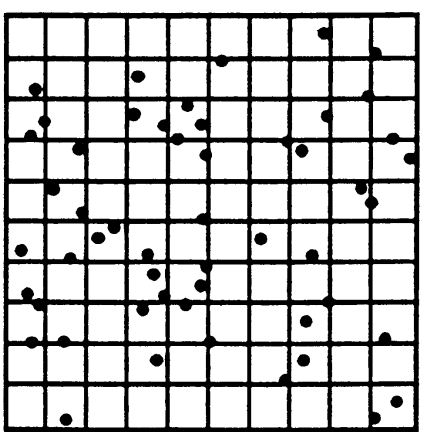

Spherons

$\mathrm{D}=0.93 \pm 0.2(\mathrm{n}=12)$

Plaques

$\mathrm{D}=0.92 \pm 0.11 \quad(\mathrm{n}=12)$
Ordered

D $>1$

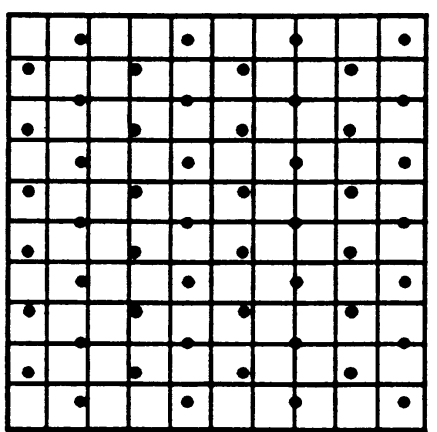

Neurons, Glial cells

$\mathrm{D}=2.15 \pm 0.2(\mathrm{n}=10)$

Vessels

Fig. 6. Schematic illustration of microspatial characterization of structures. A illustrates a cluster, such as a beehive, an anthill or polyglucosan bodies in the periventricular region. B illustrates random spacing such as a typical Poisson process, random numbers, and SP and spheron locations. C illustrates regular spacing, such as a crystal lattice, names in a phone book, bricks in a wall, most machine made goods, and neurons, glial cells, and micro vessels in the cortex. Inter-particle distances (nearest neighbour) are measured by the planar distance to the nearest next particle, which is skewed in A, randomly distributed in B, and uniform in C. Quadrat counts consist of the number of particles per box or $n \times n$ boxes, which is skewed in A, randomly distributed in B and uniform in C.

Table 5A

Individual nearest neighbour distance values (spherons)

Young controls $(N=12)$

\begin{tabular}{|c|c|c|c|c|c|c|c|c|c|c|c|}
\hline No. & Age & Sex & $\begin{array}{l}\text { Brain } \\
\text { weight }\end{array}$ & Cause of Death & $\lambda_{\mathrm{t}}$ & $d_{\mathrm{e}}$ & $d_{\mathrm{o}}$ & $D$ & $2 D_{2}$ & $\lambda q$ & $X^{2}\left(N_{x}\right)$ \\
\hline 1 & 24 & $\mathrm{M}$ & 1350 & Respiratory failure & 8.02 & 0.177 & 0.147 & 0.833 & 0.584 & 2.33 & 4.0 \\
\hline 2 & 38 & M & 1430 & $\begin{array}{l}\text { Gastrointestinal } \\
\text { hemorrhage }\end{array}$ & 7.25 & 0.186 & 0.230 & 1.24 & 1.12 & 7.25 & 2.0 \\
\hline 3 & 20 & $\mathrm{~F}$ & 1200 & Cachexia & 7.64 & 0.181 & 0.170 & 0.937 & 0.688 & 2.22 & 1.5 \\
\hline 4 & 27 & M & 1700 & Cerebral hemorrhage & 3.26 & 0.277 & 0.234 & 0.845 & 0.494 & 1.0 & 2.15 \\
\hline 5 & 26 & M & 1450 & Septicemia & 2.95 & 0.292 & 0.245 & 0.837 & 0.652 & 0.857 & 3.57 \\
\hline 6 & 20 & M & 1460 & Pulmonary edema & 2.78 & 0.299 & 0.329 & 1.10 & 1.16 & 0.81 & 5.23 \\
\hline 7 & 28 & $\mathrm{~F}$ & 1100 & Respiratory failure & 4.51 & 0.235 & 0.184 & 0.783 & 0.49 & 1.31 & 7.25 \\
\hline 8 & 21 & $\mathrm{~F}$ & 1400 & Bronchopneumonia & 9.45 & 0.163 & 0.200 & 1.23 & 1.97 & 2.75 & 11.0 \\
\hline 9 & 34 & $\mathrm{~F}$ & 1325 & Cardiac arrest & 13.1 & 0.138 & 0.131 & 0.95 & 0.67 & 3.83 & 2 \\
\hline 10 & 28 & $\mathrm{~F}$ & 1360 & Respiratory arrest & 10.3 & 0.156 & 0.121 & 0.777 & 3.70 & 3 & 11 \\
\hline 11 & 23 & $\mathrm{~F}$ & 1280 & Pulmonary embolism & 7.16 & 0.187 & 0.199 & 1.06 & 0.836 & 2.08 & 3.33 \\
\hline 12 & 20 & $\mathrm{~F}$ & 1500 & Pneumonia & 2.36 & 0.325 & 0.189 & 0.582 & 0.234 & 0.688 & 4.52 \\
\hline
\end{tabular}


Table 5B

Individual nearest neighbour distance values (spherons)

Aged controls $(N=8)$

\begin{tabular}{llllllllllll}
\hline No. & Age & Sex & $\begin{array}{l}\text { Brain } \\
\text { weight }\end{array}$ & Cause of Death & $\lambda_{\mathrm{t}}$ & $d_{\mathrm{e}}$ & $d_{\mathrm{o}}$ & $D$ & $2 D_{2}$ & $\lambda q$ & $X^{2}\left(N_{x}\right)$ \\
\hline 1 & 70 & M & 1360 & Bronchopneumonia & 2.89 & 0.294 & 0.298 & 1.00 & 0.63 & 0.84 & 2.6 \\
2 & 76 & M & 1320 & Heart failure & 6.56 & 0.195 & 0.216 & 1.11 & 9.26 & 1.91 & 3.33 \\
3 & 84 & M & 1400 & Bronchopneumonia & 3.12 & 0.282 & 0.212 & 0.75 & 0.41 & 0.91 & 4.25 \\
4 & 55 & F & 1085 & Aspiration & 2.11 & 0.345 & 0.280 & 0.812 & 0.50 & 0.613 & 4.36 \\
5 & 72 & F & 1300 & Bronchopneumonia & 1.23 & 0.450 & 0.412 & 0.916 & 0.800 & 0.357 & 3.32 \\
6 & 76 & M & 1450 & Bronchopneumonia & 2.11 & 0.345 & 0.369 & 1.07 & 0.794 & 0.615 & 2.37 \\
7 & 88 & F & 1260 & Pulmonary embolism & 2.75 & 0.301 & 0.357 & 1.18 & 0.947 & 0.8 & 2.47 \\
8 & 70 & M & 1650 & Bronchopneumonia & 7.12 & 0.190 & 0.173 & 0.92 & 1.57 & 2.07 & 7 \\
\hline
\end{tabular}

Table 5C

Individual nearest neighbour distance values (SP)

Alzheimer's disease $(N=12)$

\begin{tabular}{|c|c|c|c|c|c|c|c|c|c|c|c|}
\hline No. & Age & Sex & $\begin{array}{l}\text { Brain } \\
\text { weight }\end{array}$ & Cause of Death & $\lambda_{\mathrm{t}}$ & $d_{\mathrm{e}}$ & $d_{\mathrm{o}}$ & $D$ & $2 D_{2}$ & $\lambda q$ & $X^{2}\left(N_{x}\right)$ \\
\hline 1 & 91 & $\mathrm{~F}$ & 1100 & Aspiration & 2.06 & 0.348 & 0.250 & 0.719 & 1.44 & 0.6 & 1.33 \\
\hline 2 & 62 & M & 1320 & Bronchopneumonia & 8.25 & 0.174 & 0.72 & 0.989 & 0.31 & 2.4 & 4.33 \\
\hline 3 & 60 & $\mathrm{~F}$ & 1210 & $\begin{array}{l}\text { No single anatomical } \\
\text { cause }\end{array}$ & 21.76 & 0.107 & 0.090 & 0.842 & 0.48 & 7.5 & 2.00 \\
\hline 4 & 66 & M & 1320 & Lobar pneumonia & 1.92 & 0.144 & 0.105 & 0.917 & 0.52 & 5.6 & 6.0 \\
\hline 5 & 81 & M & 1370 & Cardiac arrhythmia & 19.76 & 0.112 & 0.101 & 0.901 & 0.47 & 5.75 & 2.0 \\
\hline 6 & 57 & $\mathrm{~F}$ & 1220 & Bronchopneumonia & 22.68 & 0.105 & 0.081 & 0.771 & 0.37 & 14.5 & 2.0 \\
\hline 7 & 57 & $\mathrm{~F}$ & 1180 & Bronchopneumonia & 49.83 & 0.071 & 0.076 & 1.07 & 0.72 & 14.5 & 2.0 \\
\hline 8 & 92 & M & 1135 & $\begin{array}{l}\text { Ruptured aortic } \\
\text { aneurysm }\end{array}$ & 14.89 & 0.130 & 0.132 & 1.02 & 1.32 & 4.33 & 1.0 \\
\hline 9 & 87 & $\mathrm{~F}$ & 1050 & Pulmonary embolism & 15.81 & 0.126 & 0.117 & 0.931 & 0.55 & 4.6 & 6.0 \\
\hline 10 & 90 & $\mathrm{~F}$ & 1085 & Bronchopneumonia & 19.93 & 0.112 & 0.114 & 1.02 & 0.66 & 5.8 & 3.0 \\
\hline 11 & 80 & M & 1280 & Respiratory failure & 32.07 & 0.088 & 0.075 & 0.851 & 0.49 & 9.33 & 2.0 \\
\hline 12 & 69 & M & unavailab & Bronchopneumonia & 13.75 & 1.35 & 0.128 & 0.946 & 0.52 & 4.0 & 2.5 \\
\hline
\end{tabular}

Table 6

Summary of spatial distribution values of spherons, SP, and controls

\begin{tabular}{lcccccc}
\hline Structures & $N$ & $D$ range & mean & s.d. & $\begin{array}{c}\text { proportion } \\
\text { significant } D_{2}\end{array}$ & $\begin{array}{c}\text { proportion } \\
\text { significant Q.C. }\end{array}$ \\
\hline 1. Spherons: Young normal controls & 12 & $0.582-1.24$ & 0.931 & 0.196 & 0.08 & 0 \\
2. Spherons: Non-demented old controls & 8 & $0.75-1.18$ & 0.970 & 0.148 & 0 & 0 \\
3. SP: Alzheimer's disease & 12 & $0.719-1.07$ & 0.915 & 0.105 & 0 & 0 \\
4. periventricular CA & 10 & $0.14-0.52$ & - & - & 100 & 100 \\
5. N,G & 10 & $1.8-2.32$ & 2.15 & 0.20 & 100 & 100 \\
6. V & 10 & $1.52-1.82$ & 1.61 & 0.18 & 100 & 100 \\
\hline
\end{tabular}




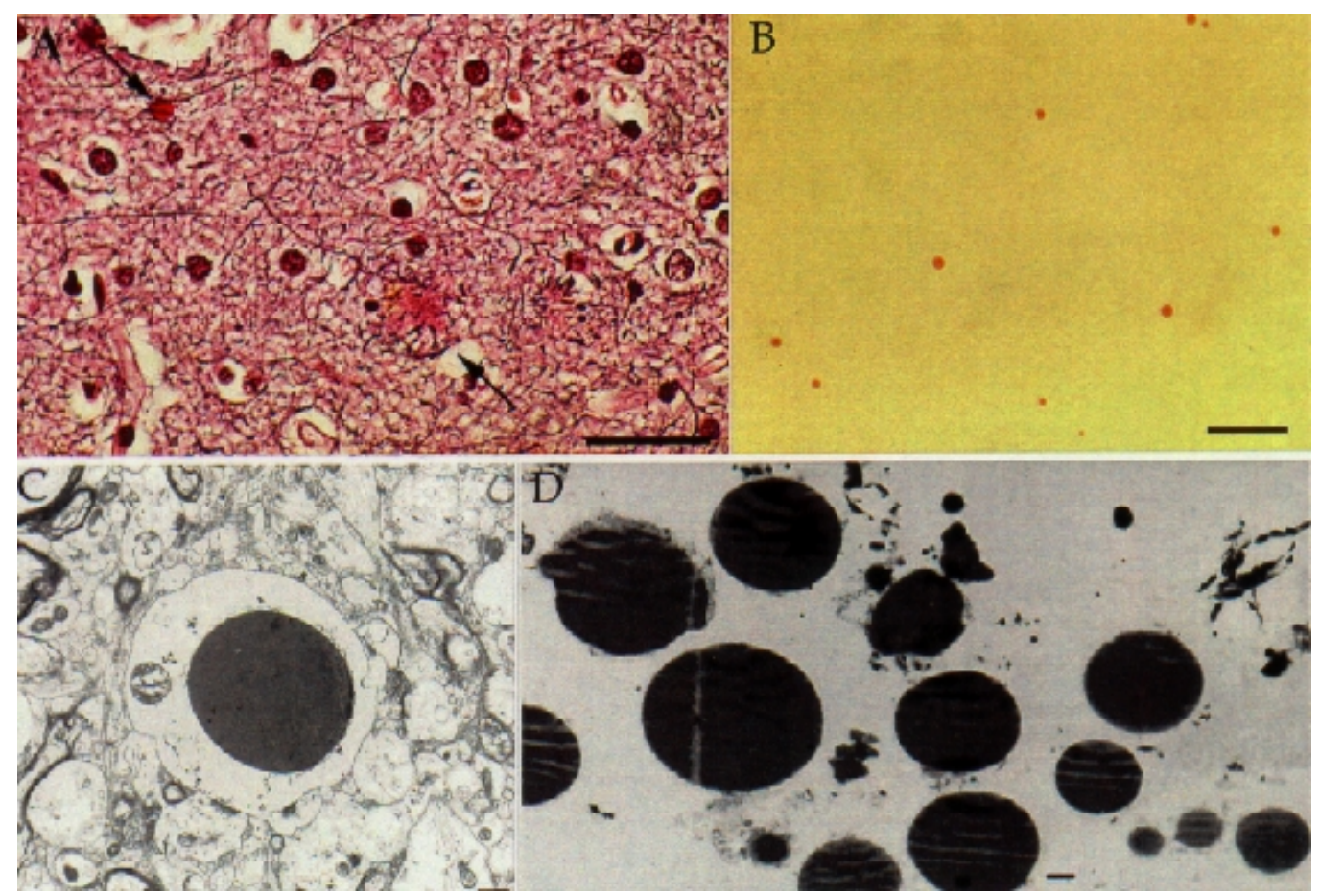

Fig. 7. Spheron preparations from human brains are essentially pure by microscopic criteria. Samples of spheron preparations were examined by both light $(\mathrm{LM})(\mathrm{A}, \mathrm{B})$ and transmission electron $(\mathrm{C}, \mathrm{D})$ microscopy $(\mathrm{TEM})$. The purified spheron samples $(B, D)$ resemble the spherons found in situ $(A, C)$. Light micrographs of purified preparations were taken after staining a $50 \mu 1$ sample of purified spheron preparation with eosin (B). Brain sections were prepared and stained for LM from formalin fixed tissue embedded in paraffin, and stained with Bodian and eosin, with a section thickness of $6 \mu$ and for TEM from glutaraldehyde fixed tissue embedded in Epon resin, sectioned at $0.1 \mu$, and stained with uranyl acetate and lead citrate. Scale bars indicate $40 \mu \mathrm{m}(\mathrm{A}, \mathrm{B})$ or $500 \mathrm{~nm}(\mathrm{C}$, D). Arrows in A indicate spheron (top left) and senile plaque (lower tight).

The Chi-square values for the quadrat count tests for spherons or SP never attained statistical significance at the 0.05 level indicating that there is no significant departure from randomness. The Chi-square values for $\mathrm{N}$ and $\mathrm{V}$ were in all instances significant, indicating non-random (i.e. regular) distribution, with comparatively minimal variation in field frequencies.

\section{Species Comparison for Presence of Spherons}

Spherons were seen in cerebral cortex of monkeys, dogs, cows, pigs, racoons, deer, goats, sheep, horses, and bears. In the limited material examined, spherons were not found in birds, squirrels, mice, guinea pigs, rats, chickens, and birds. None were seen in rabbits, and their presence was not certain in cats.

The spherons in the brains of other species had the same histological appearance as spherons in humans. They were, however, considerably smaller, generally in the range of $1-4 \mu \mathrm{m}$ in diameter.

\section{Isolation of Spherons}

Spherons have been isolated and purified as protein bodies sedimenting with a density of $\approx 1.25 \mathrm{~g} / \mathrm{ml}$ by sucrose density gradient centrifugation of human brain homogenates. To estimate the purity of the preparations, the samples were examined by both light and electron microscopy (Figure 7). 


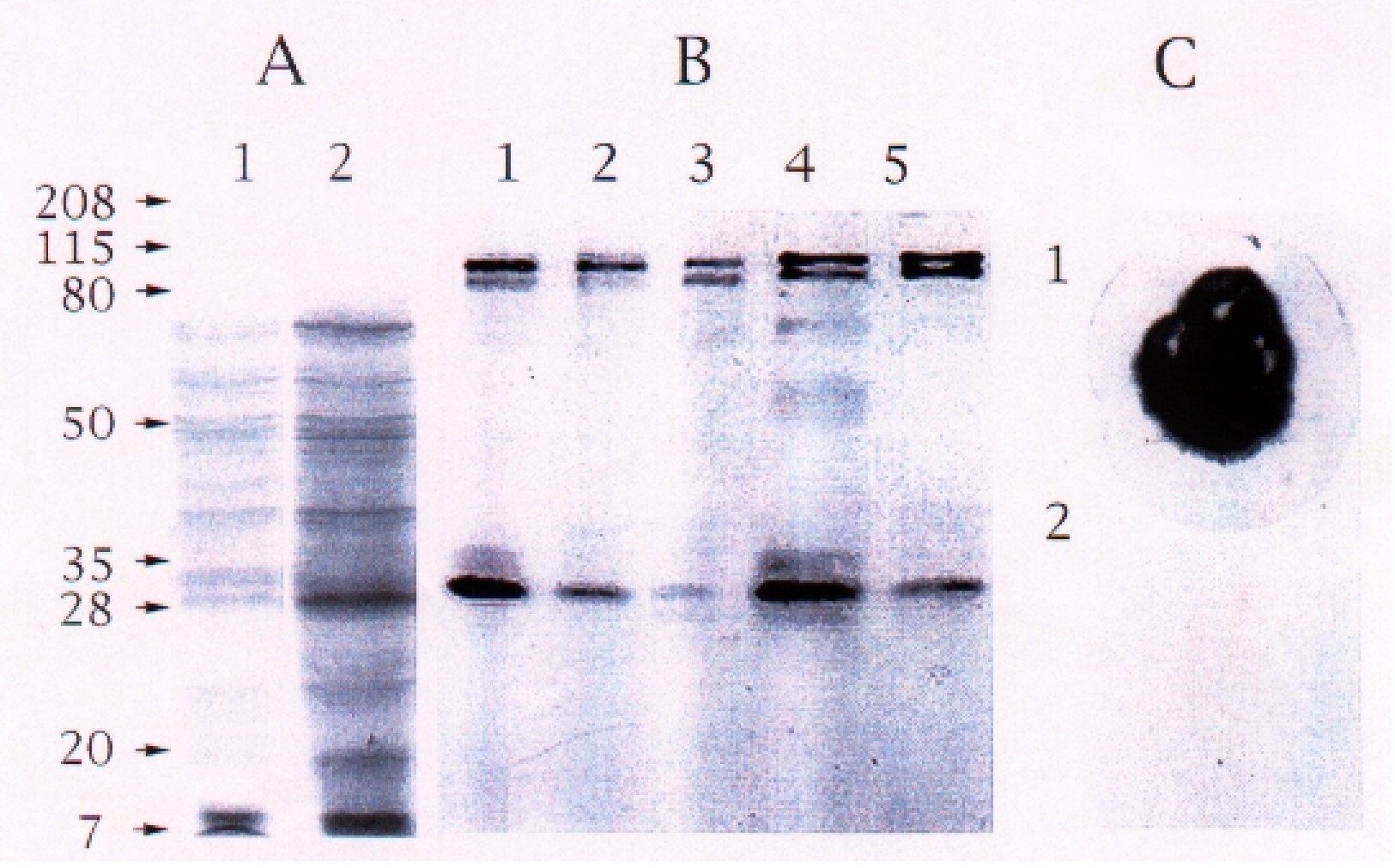

Fig. 8. Purified spherons analysed by gel electrophoresis contain SP markers. A representative sample of purified spherons containing roughly $10 \mu \mathrm{g}$ protein was solubilized in standard gel electrophoresis sample buffer and electrophoresed on SDS-PAGE (A). Separate lanes were either stained with coomassie blue (lane 1 of A) or silver (lane 2 of A) or were transferred to nitrocellulose for immunoblotting (B). Antibodies for immunoblotting were directed against the APP (Boehringer Mannheim). Antibody reaction was visualized using a peroxidase labeled secondary antibody and a chemiluminescent detection method (Boehringer). Dot blots stained with anti- A- $\beta$ (No. 1) and unstained control (No. 2) without primary antibody (C).

The size of the spherons in the purified preparations (Panels B and D) is similar to that observed for spherons in situ (Panels A and C) when either light or electron microscopy is used. There is no apparent contamination by other protein-containing organelles as judged by the lack of other staining bodies in these preparations. The presence of spherons in fractions containing up to $55 \%$ sucrose and the inferred density $(\approx 1.25 \mathrm{~g} / \mathrm{ml})$ suggests that spherons are composed of tightly packed proteins. Spheron yield varied enormously from brain to brain, from nearly zero discernible difference between $\mathrm{AD}$ and normal for extractability. Age differences in normals do not appear to affect extractability.

\section{Gel Electrophoresis and Immunoblotting of Spheron Samples}

The homogenates of purified spheron preparations display a relatively constant protein profile when analyzed by SDS-PAGE (Figure 8). It is unlikely, given the high concentration of sucrose required to purify spherons, that soluble cytoplasmic contaminants would contribute to 
these protein profiles. Thus far no differences in spheron gel electrophoretic band patterns have been detected between $\mathrm{AD}$ and normal, or between young and old.

Immunoblotting experiments using anti-A- $\beta$ 1-40 or anti-APP (A-695) (Figure 8B) clearly show the presence of these SP associated proteins in the spheron preparations. As noted above, it is unlikely that additional organelles or cytoplasmic contaminants could contribute A-695 or A- $\beta$ antigens in these quantities to our preparations. An A- $\beta$ band can be stained after electrophoresis but it is more difficult to run because it is extracted or solubilized poorly from spherons. Dot blots more readily show A- $\beta$ staining when disrupted spheron material is directly applied to nitrocellulose (Figure 8C). Proteins immunoreactive with APP (Nexin-II) are observed at molecular weights of $90 \mathrm{kDa}$ and 28 $\mathrm{kDa}$ in all preparations of spherons. These observations have been independently verified by scientists in other major laboratories to whom we have provided spheron samples (unpublished data).

\section{In Vivo Experimental Transformation of Spherons into Amyloid}

When injected into tissues such as liver, kidney or skin (Figure 9A,B) the injection site forms an inflammatory focus and individual spherons undergo a transition to amyloid. When viewed at higher magnification, the red to green birefringence of the amyloid can be seen (Figures 9C,9F). The conversion of spheron to amyloid was also observed when purified samples were injected into brain tissue (Figure 9D). The purified spheron preparations consist essentially of only spherons without any amyloid. The dramatic and masssive amount of experimental amyloid production is quantitative evidence that the spherons are the source of the experimental amyloid. These in vivo experiments (and the in vitro experiments described below) have been independently verified in other institutions to whom we have provided spheron samples (unpublished data).

\section{Immunohistochemical Staining of Spheron Material}

Injected spheron material can be stained for APP (Figure 10). Staining has been found in degenerated spherons after injection and in in vitro preparations.

\section{In Vitro Experimental Transformation of Spherons into Amyloid}

Mechanical breakage results in long smears of congophilic birefringent green material which can be seen on microscope slides (Figures 9E,9G). When the spheron suspension is pelleted by centrifugation, the supernatant does not convert to amyloid deposits under the same conditions. The purified spheron preparations, consisting essentially of only spherons, contain no fibrillar amyloid, and in vitro experimentally produced amyloid material no longer contains any spherons. Therefore the massive experimental production of amyloid provides further quantitative evidence that the spherons are the source of the experimental amyloid.

\section{Experimental Drug Blockers of Spheron Transformation}

The utility of spherons for screening compounds that block amyloid production was demonstrated using in vitro and in vivo spheron transformation to amyloid. Most compounds tested (see Methods) had no effect on spheron transformation to amyloid. A few compounds, however, blocked the transformation to amyloid in a reproducible manner. As shown in Figure 11, for example, spherons treated with $100 \mu \mathrm{M}$ cyclophosphamide do not produce amyloid when injected into the live animal. Instead the spherons disperse into smaller particles which retain the staining properties of the intact spherons. These smaller fragments are gradually ingested by macrophages and are removed from the injection site but have not transformed into amyloid even after 1 to 2 weeks (Figure 11). We have designed and synthesized several new chemical entities (D2858, D1-0872; D1-4421) 
which consistently block spheron transformation to amyloid plaques. The spherons are subsequently engulfed by macrophages and removed by the reticulo-endothelial system.
These examples demonstrate that spherons can be utilized in a screening model to develop amyloid blockers as therapeutic agents for AD.

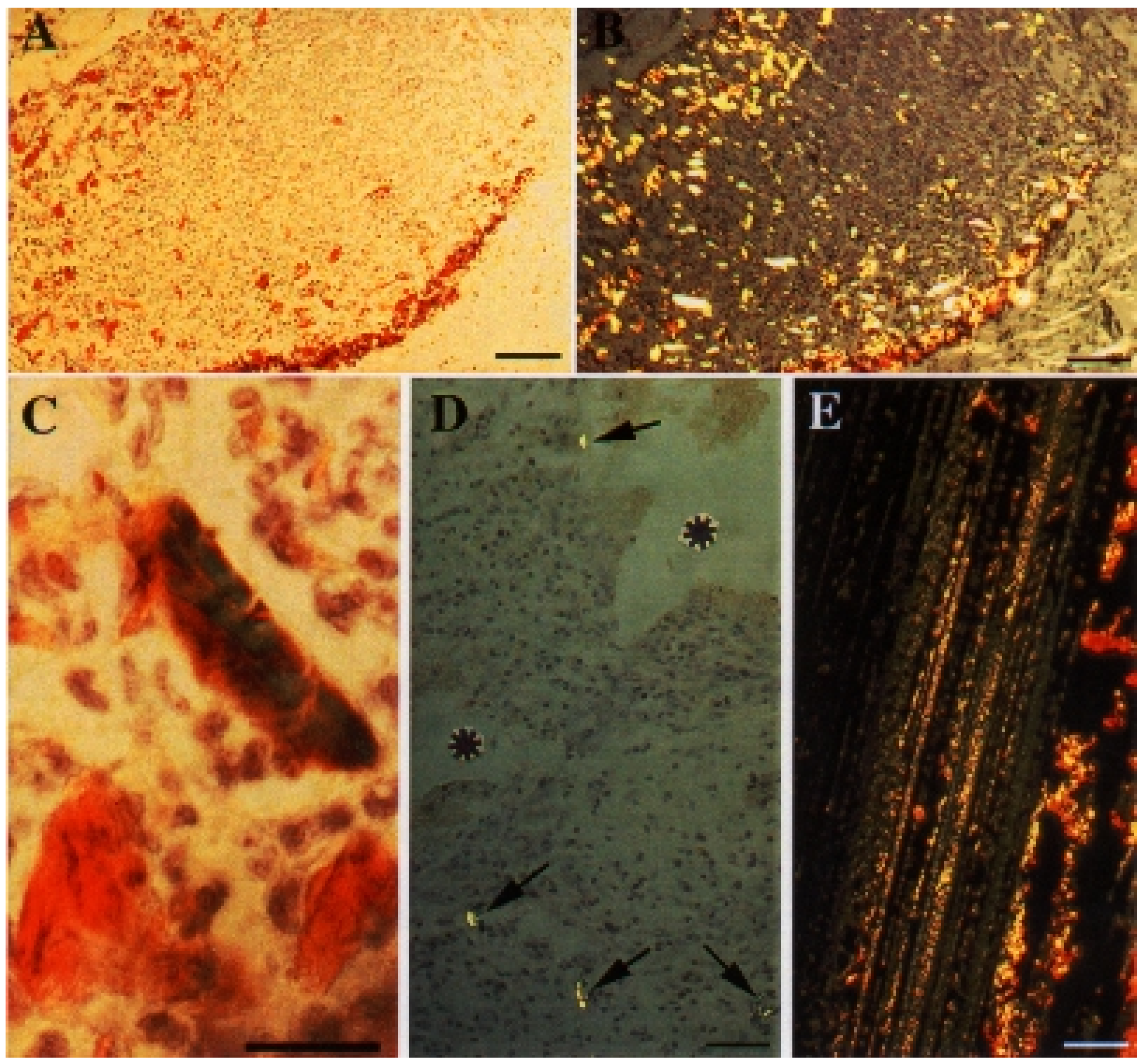

Fig. 9. Spherons can form birefringent amyloid. Spherons injected in vivo produce amyloid deposits which are congophilic (A) and birefringent when observed with crossed polarizing filters (B: bar=75 $\mu$; H: X 450) (skin). The amyloid deposits (arrows) are observed adjacent to the needle track (asterisks) in brain (D: bar=40 $\mu$ ). When viewed under higher magnification, amyloid deposits formed in vivo show the red to green birefringence $(\mathrm{C}$ : bar=20 $\mu$; F: bar=25 $\mu$ ). When mechanically disrupted, spheron preparations produce large quantities of congophilic green birefringent amyloid (E, G: bar=25 $\mu$ ). 
$\mathbf{F}$

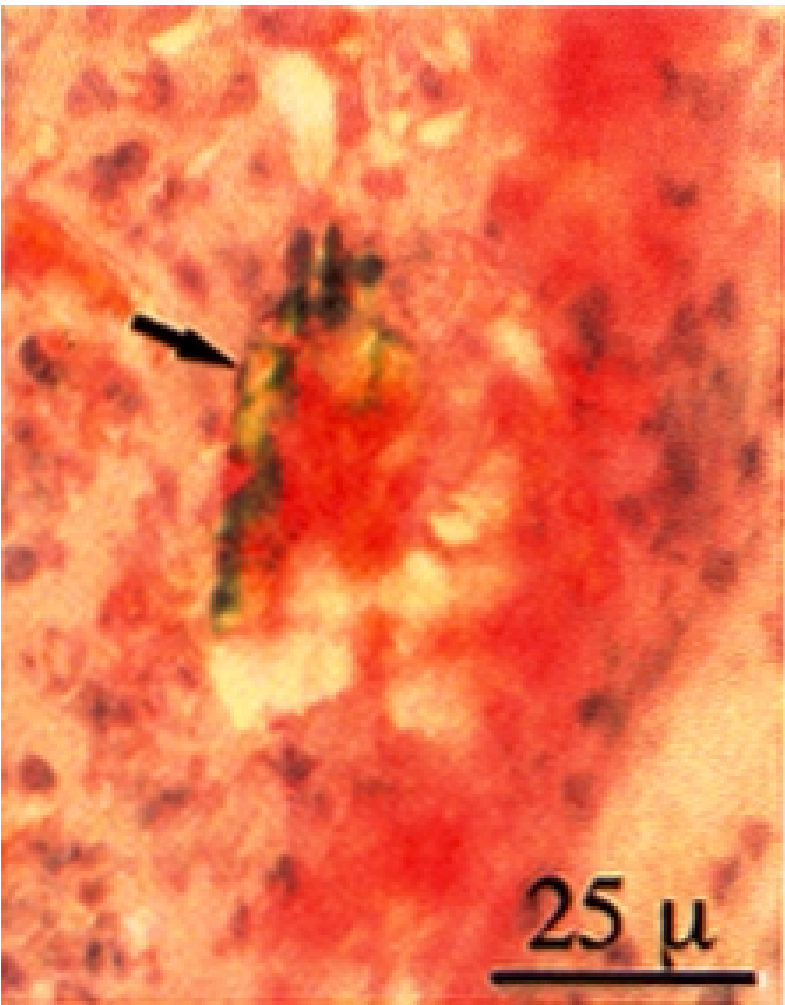

G

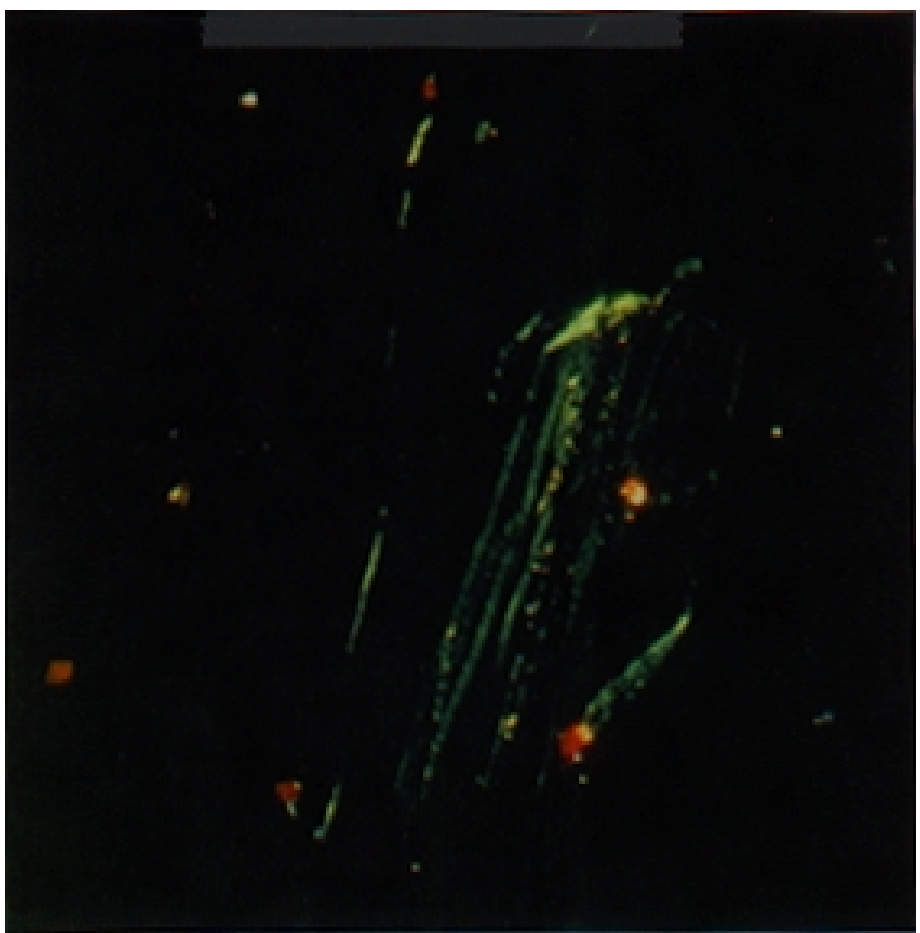

Fig. 9. (continued) 


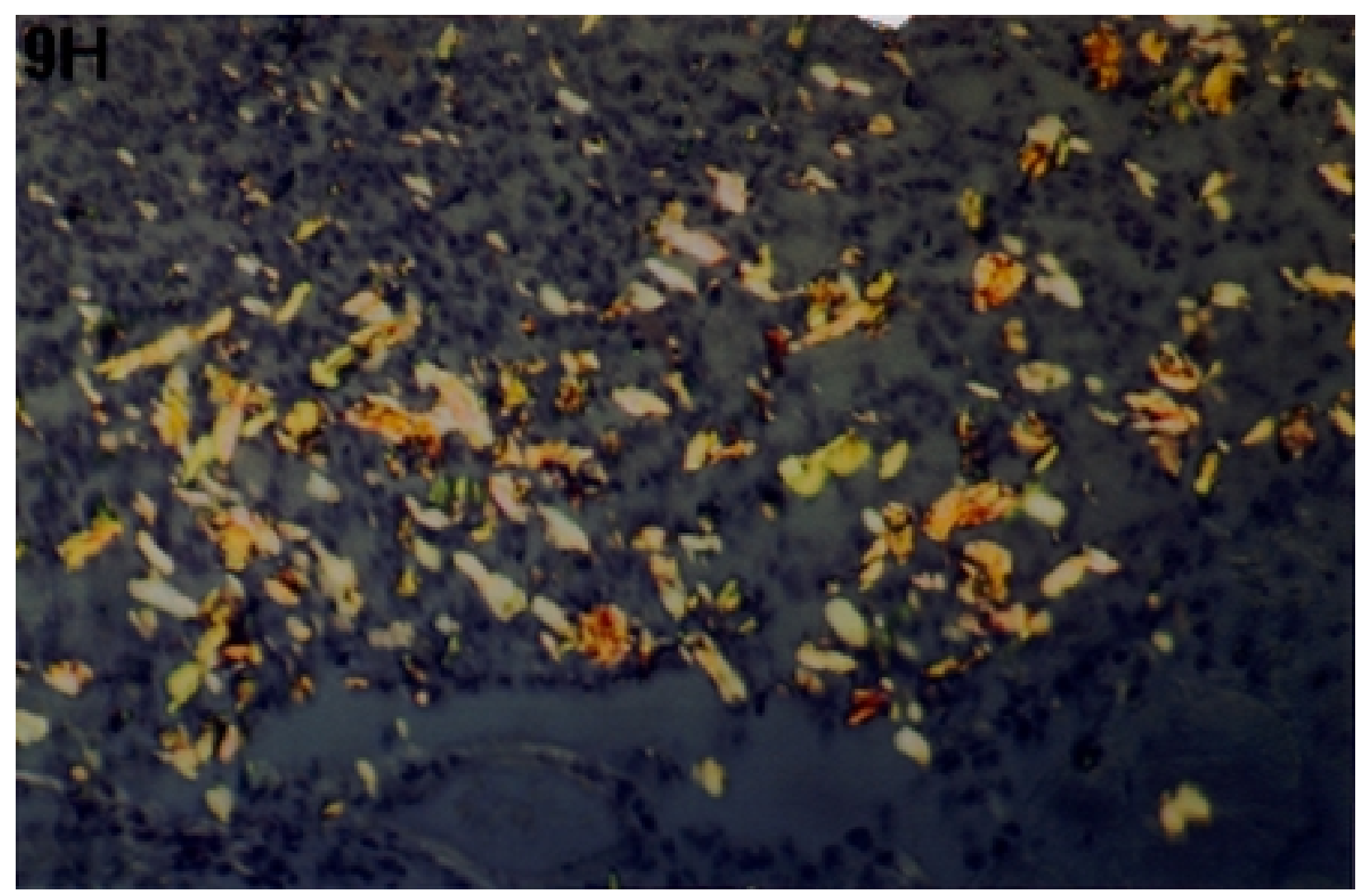

Fig. 9 (continued)

\section{DISCUSSION}

\section{Overview}

We have found 10 fundamental relationships between spherons and SP (Table 7). Moreover, we have listed 20 criteria of validity for an SP causal entity (Table 8), all of which can be satisfied by spherons. The data shows that spherons are solitary intraneuronal proteinaceous physically dense gray matter neuropil spherical bodies of unknown normal function. The average individual spheron volume progressively enlarges over a person's lifetime up to the size range of 10 $\mu \mathrm{M}$ diameter. In addition to other proteins, spherons contain large amounts of amyloid proteins. After the spherons have reached a volume of about 500 cubic microns in the elderly and in $\mathrm{AD}$, their number in gray matter is significantly reduced. This loss of spherons in gray matter is numerically balanced by the new appearance of SP in the same localization from where the spherons have been lost, i.e. when one looks for spherons in histological sections of postmortem $\mathrm{AD}$ brain, one finds that the number of spherons is significantly reduced, and one also finds SP where the spherons would otherwise have been. Morphometric data shows that spherons and SP have indistinguishable localizations and spatial distributions, as well as distinctive individual size correlations. These many quantitative characteristics of spherons and SP in AD brain are not only identical in SP and spherons, but they are uniquely identical, because no other brain entities have these characteristics. Purified spherons contain the amyloid markers of SP in addition to numerous other proteins, and spherons injected into experimental animals produce SP-like lesions, which also can be stained for amyloid markers. The in vivo and in vitro transformations of spherons to amyloid plaques show that one spheron produces one 


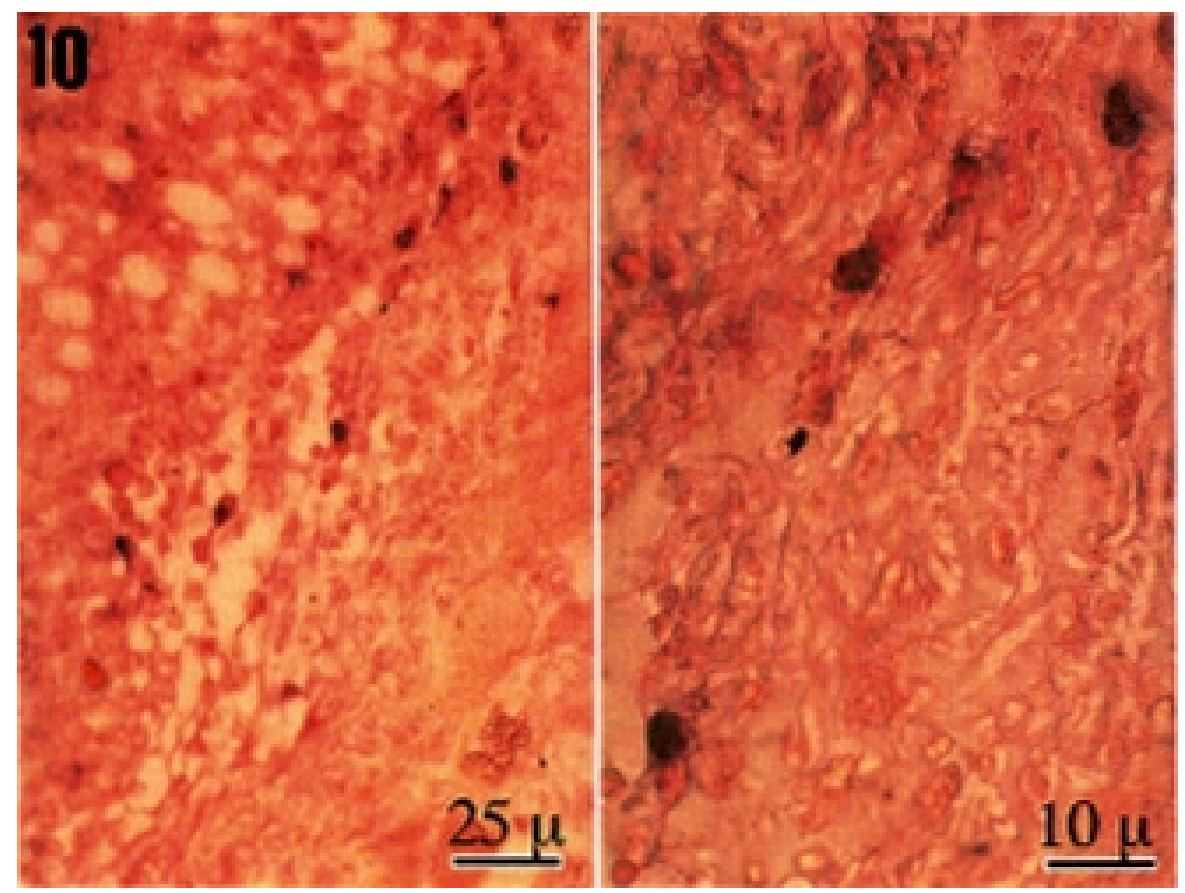

Fig. 10. Injected spherons stained for APP. Spherons injected into rat skin as in Figure 8 stained immunohistochemically with primary anti-APP. The samples were taken 24 hours after inoculation, fixed in formalin, embedded in paraffin, sectioned and stained by standard techniques. The spherons have degenerated, the antigenic sites are exposed and can be stained.

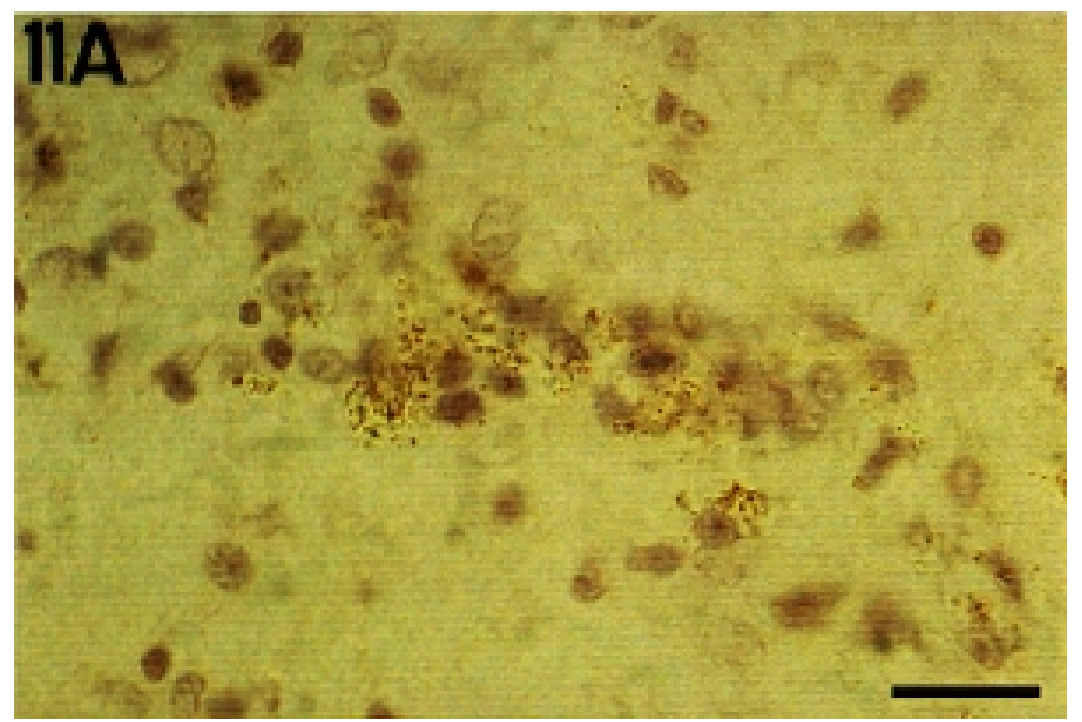

Fig. 11. Spheron transformation to amyloid plaques can be blocked with experimental drugs. When spherons are preincubated with certain exceptional experimental compounds, the spherons do not form amyloid fibrils and the spheron material can be removed by macrophages. In other instances, the spherons break up into smaller fragments before being removed. In the examples illustrated the spherons have not produced experimental SP lesions. A illustrates the use of cyclophosphamide at $10^{-3}-10^{-4} \mu \mathrm{M}$, with the spherons breaking up into tiny fragments which are subsequently phagocytosed (bar $=18 \mu$ ). B illustrates spheron material removed by macrophages $(\mathrm{bar}=10 \mu)$. 


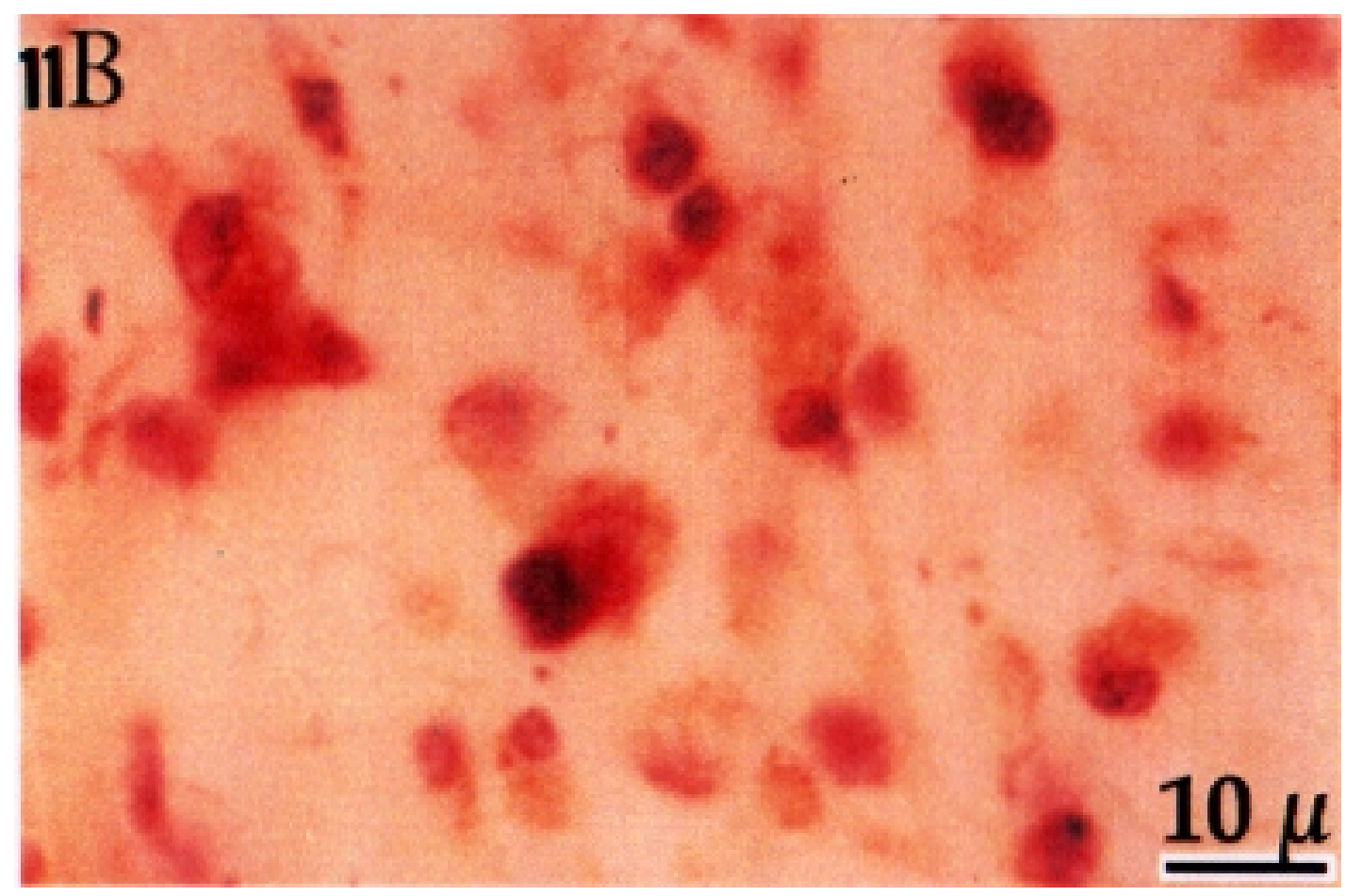

Fig. 11. (continued)

amyloid plaque of the same size range as SP in AD. A few exceptional experimental drugs (such as D-2858, D1-0872, D1-4421) appear to be capable of blocking the production of SP-like lesions brought about by spheron inoculation.

Purification of spherons with the demonstration of A-695 and A- $\beta$ presence in spherons, establishes that spherons contain the biochemical markers expected for verification of a structure implicated in the formation of SP. The in vitro and in vivo experimental production of experimental amyloid plaques from purified spheron preparations represents the first and only instance in which amyloid plaques of SP size have been consistently produced from a brain tissue derived protein or structure (as opposed to synthetic or recombinant models).

In addition to the above evidence for a spheron theory, it is important to consider fundamental data and reasoning which establish the specific relationships of spherons and SP in human brain, which are also basic to establishing relevance of spherons to $\mathrm{AD}$, concepts and data that are derived purely from studies of human brain tissue.

The unique relationship of spherons and SP are discussed below and summarized in Table 7 , and the criteria of validity are summarized in Table 8. Experimental in vivo and in vitro transformations of spherons into amyloid plaques, and demonstration of amyloid biochemical markers in spherons, have been independently confirmed in other major laboratories (unpublished data).

\section{Descriptions of SP}

From the time of Marinesco and Alzheimer it has been recognized that the brain in $A D$ contains significant numbers of prominent, round, non-confluent, large (up to 100 microns diameter) abnormalities which are called SP (in addition to other lesions which are not discussed here). A century of neuropathological observations of SP has revealed that on section SP are comprised to varying degrees of 1 . amyloid, 2. distorted and degenerated neuronal 
Table 7

Identical characteristics of SP and spherons

\begin{tabular}{|c|c|c|}
\hline & SP & Spherons \\
\hline Brain nuclear location & $\begin{array}{l}\text { All gray matter nuclei, lesser in } \\
\text { cerebellum. Not found in white } \\
\text { matter. Not found in other tissues }\end{array}$ & Same \\
\hline Histological location & $\begin{array}{l}\text { Non-perikaryal, predominantly in the } \\
\text { neuropil }\end{array}$ & Same \\
\hline Ultrastructural location & In relation to small neurites & Same \\
\hline $\begin{array}{l}\text { Frequency per unit volume brain } \\
\text { Mean number } \\
(\text { Spherons }+ \text { SP) }\end{array}$ & $\begin{array}{l}\mathrm{AD} \\
(222+352)\end{array}$ & $\begin{array}{l}\text { Young normal controls } \\
(581+0)\end{array}$ \\
\hline No significant difference & 574 & 581 \\
\hline $\begin{array}{l}\text { Comparative size } \\
\text { Ratio of hippocampal cortex to } \\
\text { temporal neocortex calculated } \\
\text { spheron and SP volumes }\end{array}$ & $\begin{array}{l}\text { Ratio of hippocampal cortex to } \\
\text { temporal neocortex calculated SP } \\
\text { volumes } 5.36\end{array}$ & Age $0-10: \quad(13.9 / 7.2): 1.91$ \\
\hline $\begin{array}{l}\text { Equivalent topographical size gradient } \\
\text { (Chi-square } p<0.001 \text { ) } \\
\text { with non-overlapping distributions }\end{array}$ & $\begin{array}{l}\text { Mean hippocampus SP diameter } 61.8 \\
\text { Mean neocortical SP diameter } 34.1 \mu\end{array}$ & $\begin{array}{ll}20-40: & (27.4 / 12.4): 2.21 \\
65-90: & (65.5 / 28.5): 2.30\end{array}$ \\
\hline Biochemical characteristics & Contain APP and A- $\beta$ & same \\
\hline \multicolumn{3}{|l|}{ Microspatial Distribution } \\
\hline \multirow[t]{2}{*}{$\begin{array}{l}\text { Nearest neighbour distance } \\
\text { distributions ( } \mathrm{D} \text { value) }\end{array}$} & 0.915 & $\begin{array}{ll}\text { young normals } & 0.931 \\
\text { old normals } & 0.970\end{array}$ \\
\hline & No significant difference from random & No significant difference from random \\
\hline \multirow[t]{3}{*}{ Quadrat count measures } & $\mathrm{X}^{2} \quad 3.01$ & young normals $\mathrm{X}^{2} \quad 4.80$ \\
\hline & & old normals $\quad X \quad 3.71$ \\
\hline & Random spatial patterns & Random spatial patterns \\
\hline $\begin{array}{l}\text { Comparative neurology } \\
\text { (species specificity) }\end{array}$ & $\begin{array}{l}\text { Absent in rodents, birds, other small } \\
\text { mammals and non-mammals. } \\
\text { Present in very old primates, dogs, } \\
\text { pigs, bears. }\end{array}$ & Same \\
\hline Geometrical characteristics & Spherical & Same \\
\hline Topological characteristics & $\begin{array}{l}\text { Unitary: no union or confluence of } \\
\text { several SP lesions. No enlargement } \\
\text { of single lesion past limit. }\end{array}$ & Same \\
\hline
\end{tabular}


Table 8

Criteria of validity for a senile plaque causal entity evidence for the relationship between spherons and SP

1. Selective brain nuclear location topographically

2. Histological localization

3. Ultrastructural localization

4. Species specificity

5. Number per unit volume brain tissue

6. Spatial distribution

\section{Size characteristics}

8. Geometrical characteristics

9. Topological characteristics

10. Time/Age characteristics

\section{Quantitative in situ precursor-product correlation}

12. Focal concentration /concentration gradient characteristics

13. Intermediary stages identifiable consistent with above criteria (in particular $1,2,3,6,9,10$ )

14. Precursor present in normal brain exclusively localized and quantified as above

15. Precursor extractable from human brain in natural form in unit quantal package

16. Precursor material in its natural form unique to Both spherons and SP are not known to exist in other tissues. brain

17. Extracted precursor from human brain capable of Human spherons in vitro experimentally reproduce the reproducing disease lesions in vitro biochemical and optical microscopic criteria of SP.

18. Extracted precursor from human brain capable of Human spherons injected into rodent brains reproduce human reproducing disease lesions after inoculation into brain SP-like lesions in rodent brains at the sites of the injections of experimental animal such as rodent

19. Induced lesions from natural extracted precursor In experiments in vitro and in vivo, one discrete unit of spheron material from human brain results in 1:1 quantitative produces one discrete unit of full-sized SP lesion.

balance

20. Biochemical analysis of material from precursor Spherons contain A- $\beta$ and APP.

Both spherons and SP are present in gray matter areas such as cerebral cortex, hippocampus, amygdala, hypothalamus, etc; both spherons and SP are usually absent from cerebellum, and ways absent from white matter.

Both spherons and SP are located in relation to neuronal processes (small neurites). primates, dogs, pigs, and bears.

Both spherons and SP occur within the characteristic numerical range.

Both spherons and SP have random distribution of inter-unit (number per unit area in a continuous grid with equal size Docampus compared to the temporal neocortex.

spherical shape.

Both spherons and SP practically never have confluence of, or ing approximately $100 \mu$ diameter for SP).

A significant change in number per unit volume occurs in old age. Spherons are significantly reduced in number, and SP are

The mass of the SP lesion correlates with the mass of the pheron precursor in quantitative terms.

satisfy a critical concentration requirement for SP amy formation. Spherons also can satisfy the requirement for a source of an internal high to external low concentration gradient of SP amyloid.

Spherons are present in every normal brain and therefore can account for SP presence (individually in fully developed form) in lesser quantity in age-matched non-AD controls.

proms extracted from brain are unit-sized as they are in situ in brain. One extracted spheron from brain satisfies the above listed criteria of size, geometry, and topology.

consistent with biochemical markers of disease lesions 


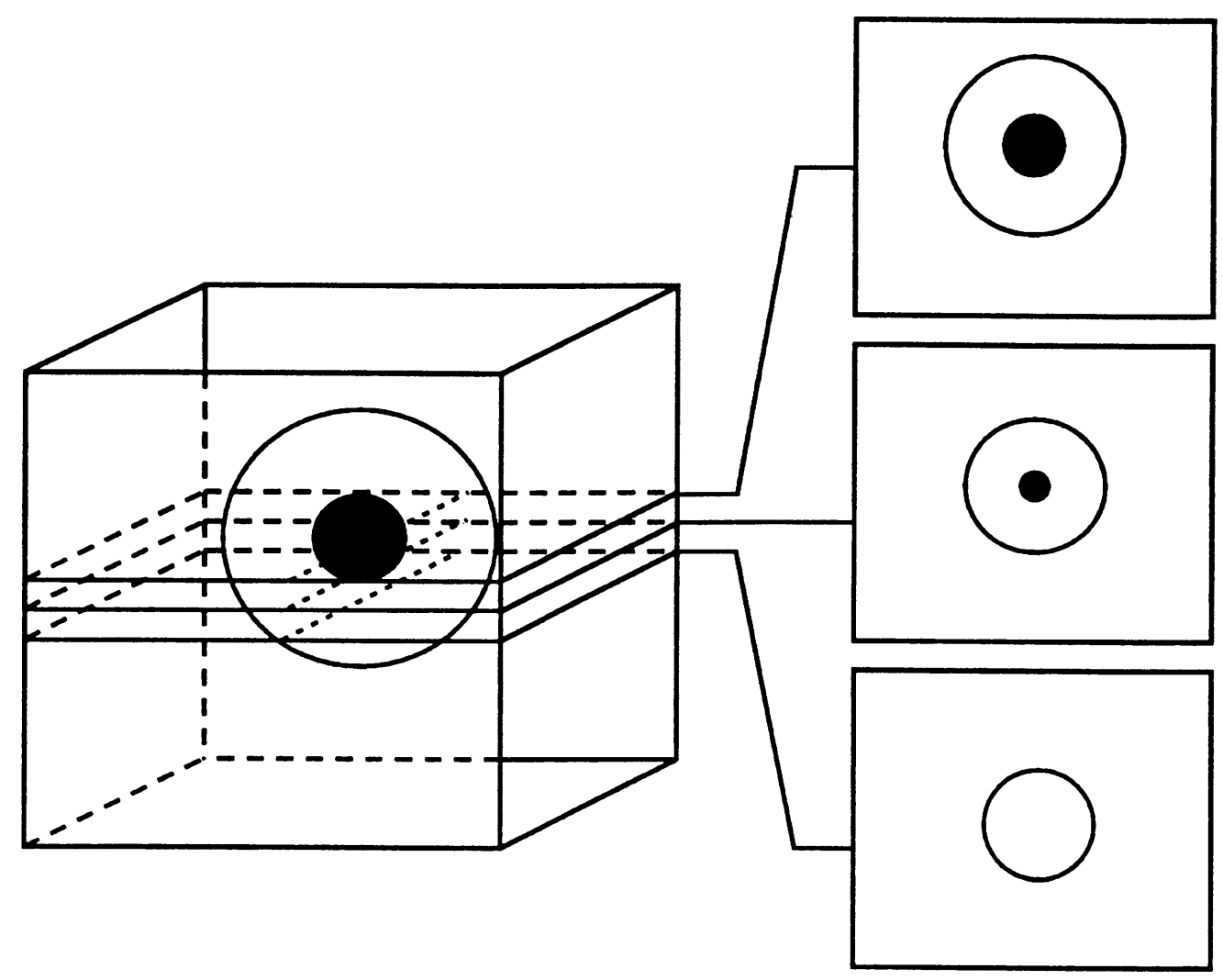

Fig. 12. Schematic illustration of the effect of sections on apparent structural heterogeneity. The simplified diagram shows variability of sectional appearance of an object. Although the object in the box is one object (a black ball embedded within a white ball) three exemplary sections from the same object produce three profiles that can be misconstrued to represent more than one different object (such as an object without a black ball, different sized objects with different proportions, etc.).

processes, and 3. peripheral reactive glia. Many quantitatively minor (in relation to the volume of the SP) biomarker molecules have been histochemically stained in SP in the past fifty years. Practically every tested serum or brain protein or polypeptide and other molecules (too numerous to cite here) have been found in SP, which is to be expected considering the enormous volume of disrupted brain tissue in one SP (up to 500,000 cubic microns). SP amyloid is red to green birefringent with polarized light when stained with Congo red; it is also stained by other methods such as periodic acid Schiff or thioflavine $S$; it can be immuno-histochemically stained for A- $\beta$, the 40 to 43 amino acid peptide which has been purified and sequenced from cerebrovascular (36) and SP amyloid; and has an ultrastructural appearance typical of most amyloid fibrils (5). Descriptive classifications of SP notwithstanding, no method has ever been devised nor data achieved of two or more timepoint samples of any sort from the same individual SP. In other words, the time course of SP evolution has never been scientifically demonstrated. A review of the myriad descriptive classifications of SP from the past century up to and including the present is beyond the scope of this paper, except to note categorically that none of them have been tested let alone proven. Every time a new staining or visualization method has been devised, new classifications have appeared in the literature based on the new staining patterns of single time point samples of SP. A second problem has been lack of controls for 
intrinsic sectional variability of inhomogeneous objects, as schematically shown in Figure 12. Kimura et al found that the same brain was classified (in terms of proportions of types of SP) differently when studied in serial sections of SP than when studied by random sections, and that most individual SP could therefore be described as mixtures of some of the classification subtypes (37), in other words, that SP heterogeneity is dramatically less than otherwise presumed.

\section{Amyloid Metabolism and SP}

SP are composed principally of amyloid amongst distorted nerve cell processes. Amyloids (the word meaning starch-like referring to staining) are a biochemically heterogeneous group of $\beta$-pleated sheet fibrillar protein materials which were one of the first known microscopic changes of human disease, being described in non-neurological conditions by Virchow over 50 years before cerebral amyloid was recognized in SP. Cerebral amyloid has been recognized morphologically in SP for a century; cerebrovascular amyloid was extracted by Glenner and Wong (1984) (36), their amyloid (A$\beta$ ) sequence leading to the recombinant precursor generally called APP, which is the same as Nexin-II, a membrane spanning protein which was known earlier, and which is found throughout the body (38-44). For the better part of a century, amyloid has been a recognized abnormality in $\mathrm{AD}$ brain with $\mathrm{AD}$ considered by many to be a cerebral amyloidosis, and therefore the "amyloid hypothesis" (45) is merely a new name. Recently many good studies have been done on amyloid metabolism, including biochemical evidence for amyloid toxicity (44). Many writers presume that because SP are loaded with A- $\beta$ then by definition a derangement of APP metabolism primarily underlies SP in the usual case of AD (45). There are hundreds of examples to illustrate in a commonsense way why it is ill-advised to make this assumption; for example, in an intracerebral hemorrhage, symptoms and damage are caused by abnormal amounts of blood in the brain but the disease is not a disorder of blood or bone marrow genes or metabolism; a sprained ankle or knee has symptoms due to increased water but has nothing to do with water metabolism, etc. The assumption that there exists a causal abnormality(ies) of APP metabolism responsible for typical SP requires proof (and adequate proof means satisfying at least the majority of the criteria listed in Table 8). Although research on cerebral amyloid marker metabolism is important (including rare genetic mutants of APP metabolism, in which the rare defects are probably causal of the rare diseases (45)), there is as yet no hard evidence that typical SP in typical AD are brought about by primary metabolic abnormalities of APP unique to AD.

\section{Geometrical Characteristics of SP}

Regardless of how SP are stained, the lesion is seen to be approximately circular on section. An object that is circular on cross section must be spherical in three dimensions and therefore SP are approximately spherical. The aggregates of amyloid fibrils, regardless of whether they form a dense cored mass with radiating fibrils or whether they form a looser arrangement without a dense core, are packed into a spherical space. If amyloid is being deposited, then it is exceedingly unlikely if not impossible that the deposit will take the form of a sphere. The spherical format, on the other hand, is to be expected from a point source with outward radiation. The best evidence for the above statements comes from human pathology where there are many examples of extracellular deposits of fibrils. Systemic amyloidosis involves multiple tissues such as liver, spleen, kidney, or skin, and the deposits are never spherical but instead consist of diffuse, constantly enlarging, highly irregular sheetlike masses (8). In other types of amyloidosis, such as that associated with chronic inflammation the same is true. Spherical geometry with maximal central density and radially decreasing density is generally characteristic of central origin (point source radiating outward, such as light sources, energy sources, gradients of radioactivity, sound, waves, etc.). Microdensitometric measurements show a gradient in individual SP with maximal 
density internally suggesting outward diffusion from focal regions of high density (7).

Spherons are spherical and degenerate in old age in the same anatomical (discussed below) location as SP appear in AD brain, and therefore spherons represent the only available spherical point source of the appropriate order of magnitude size in the brain to account for the spherical nature of SP. An alternative explanation is that amyloid travels to the SP from the outside in, which as discussed above is both unprecedented for extracellular fibrillar or organic deposits in human disease, and physically exceedingly unlikely. An alternative to a spheron origin for the spherical SP in this context is that another similarly sized spherical point source of amyloid provides the origin for the SP. We do not know of any such putative proteinaceous cerebral source. The spherical nature of SP thus strongly suggests that SP are not formed from circulating or otherwise derived "outside-in" deposits of amyloid materials, but rather from a spherical "inside-out" point source, and spherons are the only candidate source known to date which can satisfy this criterion. Others still refer to the spherical nature of SP as a major unsolved enigma in $\mathrm{AD}$ (45).

\section{Topological Characteristics of SP}

With reference to SP, the topological aspects of interest are (A) how the spherical SP enlarges and (B) whether SP ever fuse or touch each other. Other amyloids, such as in systemic amyloidosis, form masses of irregular sheetlike aggregates that continue to enlarge to comparatively huge proportions. For example, the liver or spleen in systemic amyloidosis can become massively enlarged with amyloid (spleen weight in amyloidosis can be over 800 g., compared to a normal adult range of 140 to $170 \mathrm{~g}$ ) (8). Cerebral amyloid, which invariably leads to brain atrophy in $\mathrm{AD}$, never has masses of irregular sheetlike amyloid aggregates. SP never enlarge past their characteristic size range. When other non-SP typical extracellular deposits, such as systemic amyloid deposits or cirrhotic liver, etc., are frequent and diffuse they will begin to fuse and become confluent and large. SP are practically never confluent. Spherons are unifocal, do not enlarge past a certain size range, and do not fuse at the optical level or become confluent. These SP topological characteristics imply that SP derive from limited sources, of a specific size (because SP do not enlarge past a certain size), and furthermore that these limited sources of specific size are widely dispersed from each other (because SP do not merge or become confluent). Whatever the source of SP biogenesis, it has quantal constraints, and it cannot logically be primarily attributed to any factor(s) which are spatially continuous (such as extracellular space) or comparatively ubiquitous (such as circulation, neurons, glia, etc.).

An alternative hypothesis to the quantal nature of SP is that SP are not derived from a unit sized precursor package, but rather stop growing at a certain size due to some other constraint (such as exhaustion of a rate limiting component or cofactor for amyloid formation, or due to the onset of amyloid breakdown) that stops further amyloid deposition. In addition to there being no direct evidence for these possibilities, both would imply an irregularity in shape, and much greater variation in size of SP, neither of which is the case. An alternative to the concept of spatial dispersion of SP biogenesis is that the primary source of the amyloid is diffusely present (e.g.: in blood) but the focus of deposition is spatially dispersed (in SP) and that amyloid deposition is secondary to some other undetermined spatially dispersed process (such as selective neuronal vulnerability, metabolic changes, neurotransmitter population, etc.). This second alternative explanation requires deposition, which for spherical patterns of fibril deposition is essentially unprecedented. In addition, we do not know of any dispersed process with the same spatial pattern as SP, except for spherons.

\section{Overall Size Characteristics of SP}

Any comments about variation in size observed on sections of SP need also to take into consideration intrinsic variation of sections of spheres. In other words, the same spherical 
object of $50 \mu \mathrm{m}$ true diameter, when viewed on a random $10 \mu \mathrm{m}$ section can produce a circular section of the object that can vary from a few $\mu \mathrm{m}$ to $50 \mu \mathrm{m}$. Well known statistical distributions exist for the variation of sections of a sphere $(46,47)$. Thus when the intrinsic variation of sections of a sphere are taken into account in the observed SP sectional size variation, the result is that SP size is considerably less variable than it appears. Obviously some SP are larger than others; however, the variation is in fact rather minimal when the above sectional factors are taken into consideration. Microdensitometric studies have also shown, in addition to an amyloid concentration gradient (high central to low peripheral) within an individual SP, a fairly uniform total average quantity of amyloid per SP (7). There is important biological significance to the individual SP size characteristics. First, the low variation (in other words, compared to other processes the approximate uniformity) of SP size implies similar quantitative uniformity in the biogenetic components of the individual SP. Thus not only is the precursor quantal, but the quanta are approximately uniform. Second, the absolute amount of amyloid in an individual SP should show quantitative correlation to the biological process. Spherons compared in different gray matter areas had sectional size variation between areas very similar to that observed for SP (Table 4) and are the only known protein spheres found solitary in the neuropil. Furthermore, the protein found in one spheron is the appropriate order of magnitude quantity to match the amyloid found in one SP. In fact we know of no other regularly found uniform sized protein bodies widely present in gray matter of this order of magnitude of size. A critical concentration of protein has been shown to be required in vitro for amyloid fibril formation (48). Spherons are the only known appropriately located and appropriately sized source to satisfy this concentration requirement.

An alternative to the concept of uniformity of biogenetic factors is that a highly variable precursor mechanism results in a highly uniform lesion, in other words, that randomness produces uniformity. At a bare minimum there must be at least one significant rate limiting step in SP formation that is quantal, and that is uniform in its anatomically dispersed quanta.

\section{Topographical Size Characteristics of SP}

If the conclusions discussed above are meaningful, one would thus predict that smaller spherons lead to smaller SP, and that larger spherons might correlate with larger SP. In fact, there are two instances where this may be demonstrated. First, SP are known to be larger in man than in species such as dogs and monkeys (49-51), and we have found the spheron size to be correspondingly smaller in these species. Second, spherons and SP in the hippocampus are both larger than their equivalents in the neocortex in the same human brains (Figure 5), with a highly significant equivalent size gradient $(p<0.001)$. Our data are in agreement with other published studies on SP size in these areas (35).

Any alternative explanation for the variation in SP size in species and in gray matter areas must address why these SP are different with respect to gray matter regions. For example, since individual SP are not quantitatively uniform in gray matter regions, a local factor in SP generation must be logically implicated. With the exception of spherons, we are not aware of any other known associated factors that correlate with this size difference.

\section{Spatial Distribution Characteristics of Spherons and SP}

Spatial distribution is a nonspecific term which can be operationally defined in a variety of specific ways, depending upon the purpose chosen for study. For example, in the neuroanatomical context, distribution is generally related to relevant elements such as neurons, or cerebral blood vessels, or nuclei of the brain, or synapses, etc. We have characterized several elements of the brain including SP and spherons, in relation to themselves, in order to make a quantitative classification. The results for normal structures make intuitive sense: normal structural elements such as neurons, glia and vessels are 
almost perfectly regularly spaced in any given microscopic field, and measures in quadrat counts and nearest neighbour distances are minimally variable, and significantly different from random. Periventricular polyglucosan bodies (corpora amylacea) which form closely packed clusters are skewed by these measures. The inter-SP distance distributions in cortex were indistinguishable from random, as were also the inter-spheron distance distributions. Thus not only are spherons and SP correlated by being indistinguishable from each other in microspatial pattern, but this category of microspatial pattern seems to be unique to these two elements, at least for optically visible normal elements at this frequency per unit volume order of magnitude.

An alternative to the above significance of the equivalence of these microspatial patterns of SP and spheron is that the equivalence is an irrelevant co-incidence, that both structures have the same pattern independently. However, the two structures also have the same location. Furthermore, as discussed below, before the appearance of SP in old age and in $\mathrm{AD}$, of the two only spherons are found in the spheron (SP) location. Later, when SP appear, the number of spherons is significantly reduced, in direct proportion to SP quantities. Therefore, the two structures do not have their spatial patterns independently.

\section{Frequency Characteristics of Spherons and SP}

Mean frequency (number per unit volume) of spherons is stable across age groups in normal brains. Spheron counts were found to be reduced by $57 \%$ in AD compared to brains without SP. These data indicate that the number of SP which appear in $\mathrm{AD}$ correlates with the number of spherons which have disappeared in AD. The sum of spherons plus SP is statistically constant $(\mathrm{Sph}+\mathrm{SP}=\mathrm{K})$ (t test, $p<0.0001$ ) (Figure 4; Table 2 ). The two structures are found in the same location and therefore it is logical to conclude that spherons might evolve in some way into SP.
The hypothesis against spheron loss correlating with evolution into SP is that spherons disappear independently of SP appearance. For that to be proven it is necessary to demonstate a different fate for the spherons which have disappeared. Such an alternative route and /or form of spheron reduction has not been demonstrated. In the absence of morphological evidence of the process of spheron loss, it must then be postulated that spherons disappear without a trace. Considering the biochemical evidence of extreme insolubility of spherons both in vitro and in in vivo experiments, the possibility of spheron disappearance without any morphological lesions is very remote.

It is occasionally commented that a histological section of brain from a severe case of AD can appear to be packed with SP, whereas spherons in normal brain are difficult to find and are infrequent structures, and therefore spheron theory can be dismissed out of hand for obviousness reasons. Partly this is due to spherons being on average less noticeable than SP, but the main explanation for the above misleading appearance is that SP $(25-100 \mu$ diameter) are on average an order of magnitude larger than spherons (1-10 $\mu$ diameter), and therefore a typical histological section $(5-10 \mu$ thickness) contains eccentric sections from proportionately more SP with centers out of the plane of section. A larger object with its center out of the plane of section will be contained in a greater number of sections (i.e. one given sectional plane contains pieces of the larger objects derived from a greater tissue volume source than the tissue volume source of the smaller objects), proportional to the ratio of diameters of the larger object compared to the smaller object. Stated another way in the above situation, the same $5 \mu$ diameter spheron will appear in at most two adjacent $5 \mu$ sections, whereas the same $50 \mu$ diameter SP will appear in at least ten consecutive adjacent sections (and SP are therefore proportionately overestimated in frequency per unit volume if corrections are not employed). Therefore the above appearance on sections that SP are more frequent than spherons is an appearance - but not a measurement. 


\section{Neuroanatomical Location}

SP and spherons share the same location: solitary structures, each is found in the neuropil of gray matter. Typically both are unusual in cerebellum and neither is found in white matter, or in the peripheral nervous system or other organs. With the electron microscope, spherons are found in tiny nerve processes (dendritic on the basis of occasional synaptic elements), associated with a zone of tiny axons and neurites, indistinguishable from the context of SP. We know of no other structures of this order of magnitude of size that are consistently and exclusively found in the above locations.

\section{Species Specificity}

As pointed out in Results, our studies in most species are incomplete. However, we cannot identify spherons optically in rodents after much careful study, and this correlates well with the absence of SP in rodents. Furthermore, we have been able to identify spherons in monkeys, bears, pigs, and dogs, all of which are known to develop SP to some extent (49-51). It appears that there may be a good correlation between spherons and SP in terms of species, but a larger study is needed before this can be fully resolved.

\section{Spheron Theory is Highly Compatible with the Findings of other Amyloid Research}

Several aspects of amyloid research in other laboratories dovetail neatly with our work. For example, a critical concentration of protein is required for SP fibril formation (48) (spherons are the only known appropriately located source to satisfy this criterion); SP have greatest concentration of amyloid internally with a gradient to the periphery (7) (spherons are the only appropriately located and only appropriately sized spherical amyloid diffusional source known); spherons and SP are spherical, quantal, non-confluent, contain APP markers, etc. (Table 7). In Dutch type hereditary cerebral hemorrhage with cerebral amyloidosis, there is genetic overproduction of cerebral amyloid resulting in extensive amyloid deposition in cerebral vessels. As we would expect, the amyloid overproduction in this condition does not lead to increased typical SP (52).

Studies of genetic abnormalities of APP in man provide useful information about APP, and about genetic abnormalities of APP (a protein which is found throughout the body). These genetic abnormalities of APP are not present in typical sporadic $\mathrm{AD}$ and are therefore of unproven relevance to typical SP in typical sporadic AD (which is not surprising because typical AD is not a hereditary disease).

Future work may show that rare (less than $1 \%$ of cases) hereditary genetic mutations of APP result in abnormal APP which may or may not correlate with spheron or SP changes, neither of which directly concerns ordinary spheron evolution in typical AD with typical SP. Ordinary spherons are present in every normal brain; ordinary $\mathrm{AD}$ is not hereditary disease; and typical SP are present to some degree in practically everybody if they live to be 80 to 90 or more years old.

\section{Spheron Bursting as a Physiological or Pathological Process}

Spherons are protein dense microspheres which progressively enlarge for over 70 years. We do not know if there is any normal function of spherons, but ongoing protein studies may perhaps later suggest the normal spheron function (e.g. an atypical storage body; an aberrant vestigial structure; a functional entity, etc.). Our studies so far suggest that the importance of spherons is their implication in AD. Perhaps future work will disclose protein metabolic alterations in $\mathrm{AD}$ spherons, perhaps leading to different spheron populations, more rapid growth or earlier disruption, or greater fragility, etc. Our initial work to date has not found any obvious differences between intact $\mathrm{AD}$ spherons and normal spherons. Certainly APP metabolism is relevant to spheron metabolism and growth. However, spherons are more complex than APP alone, being composed of numerous other proteins, any of which can be hypothesized alone 
or in combination to be pivotal to or modulatory of spheron growth, metabolism, and bursting.

It is also possible that burst spherons as a nidus may prove to accumulate some extra extrinsic A$\beta$ after bursting which (even if proven true) would be mechanistically secondary, quantitatively minor compared to the mass of intrinsic spheron amyloid proteins, and analogous to the many other nonspecific secondary SP biochemical components from serum and elsewhere which have been shown to end up in SP presumably after the fact (albumin, etc.). The genes producing spheron components are active in the brains of everybody by the age of one year or earlier. SP (AD) is an age-related phenomenon, rapidly increasing from $5-10 \%$ of people at age $70-75$ years, to involve up to $50 \%$ of people at age 85 . A variation of $10-15 \%$ in the overall time duration of the bursting process (i.e. from age one to 70-75, versus from age one to age 85 ) is perfectly typical for normal biological variation in individuals in normal physiological processes, such as age of onset of secondary sex characteristics, age of onset of menopause, etc. Considering that spherons are normal structures and that SP are present in some quantity in almost everybody if they live to be very old, it is logical therefore to infer that the onset of spheron bursting is probably a typical physiologically variable process. Hence we consider that some hypothetical radical difference (such as a gene or co-factor, toxin, etc.) between $\mathrm{AD}$ and normals in spheron metabolism, although of course possible, is unlikely.

In other words, the data logically suggests that the gradual enlargement of spherons leading to spheron bursting is a process that lasts a lifetime, and individual variation in the age of onset of spheron bursting (and individual variation in the total number of spheron molecules per brain) is more typical of physiological variation than it is of an all or none (present or absent) disease difference. The distinction is only academic however, because in practical terms bloated spherons are already sitting in the brains of everybody in the world of late middle age or older,and their impending bursting will need to be addressed.

\section{Summary and Conclusions}

We have found 10 fundamental relationships between spherons and SP (summarized in Table 7). We have listed 20 criteria of validity for an SP causal entity which we have found to be satisfied by spherons (summarized in Table 8). The logic and evidence of examples of alternative explanations of this data and of SP evolution have been discussed individually above. On the basis of these relationships we consider that spherons and SP are very likely to be pathogenetically related to each other. Drugs which can inhibit or block the transformation of spherons to amyloid plaques offer rational potential to be beneficial as therapy for AD.

\section{ACKNOWLEDGEMENTS}

This work was supported by Nymox Corporation. There has been considerable benefit in the past two decades from lively discussions with scientists, too many to cite individually, throughout the world. We are particularly grateful to C. Dupuis MD for ongoing comments. Individual technical assistants and colleagues providing samples and rare reagents are also too many to cite individually in entirety. We thank in particular L. Oliva MD, K. Ghanbari, and P. Salois.

\section{REFERENCES}

1. Blocq P and Marinesco G, Sur les lésions et la pathogénie de l'épilepsie dite essentielle, Semaine Médicale (Paris) 12 (1982) 445-446.

2. Alzheimer A, Über eine eigenartige Erkrankung der Hirnrinde, Allgemeine Zeitschrift für Psychiatrie 64 (1907) 146-148.

3. Alzheimer A, Über eine eigenartige Erkrankung der Hirnrinde, Zentralblatt für die Gesamte Neurologie und Psychiatrie 18 (1907) 177-179.

4. Tomlinson AE, Corsellis JAN, Greenfield's Neuropathology, 4th Edition (Edward Arnold, London, 1984) 951-1025.

5. Terry RD, Katzman R, and Bick KL (eds), Alzheimer's Disease (Raven Press, New York, 1994). 
6. Wisniewski K., Herris GA, Moretz, RC, Wisniewski, HM, Alzheimer neurofibrillary tangles in diseases other than senile and presenile dementia, Ann Neurol 5 (1979) 288-294.

7. Benes FM, Reifel JL, Majocha RE, Marotta CA, Evidence for a diffusional model of Alzheimer's amyloid A4 (beta-amyloid) deposition during neuritic plaque formation, Neuroscience 33 (1989) 483-488.

8. Robbins S, Cotran, RS, Kumar V, Pathologic Basis of Disease (Saunders, Philadelphia, 1984).

9. Averback P, Dense microspheres in normal human brain, Acta Neuropathol (Berl) 61 (1983) 148-152.

10. Averback P, Studies on the Relationship of Dense Microspheres and Senile Plaques in Human Ageing and Alzheimer's Disease, Proc IXth Int Congr Neuropath, Wien (Egermann Druckereigesellschaft, 1982) 265.

11. Averback P, Spatial distribution of dense microspheres and senile plaques in human brain, J Neuropathol Exp Neurol 41(3) (1982) 354.

12. Averback $\mathrm{P}$, Morphometric and anatomical correlation of dense microspheres and senile plaque formation in Alzheimer's disease, Can J Neurol Sci 9(2) (1982) 283.

13. Averback $\mathrm{P}$, The dense microsphere hypothesis of senile plaque formation in Alzheimer's disease, Ann Neurol 12 (1982) 1.

14. Averback $\mathrm{P}$, Correlation of measurements of senile plaques and dense microspheres in the cerebral cortex and hippocampus in Alzheimer's disease, Ann Neurol 12 (1982) 1.

15. Averback P, Population, distribution, and growth of dense microspheres in the human, Fed Proc (1982) 41.

16. Averback P, Quantitative correlations of dense microspheres and senile plaques in Alzheimer's disease, Neurology 32(2) (1982) 227.

17. Averback P, Experimental animal model of amyloid plaques using dense microspheres extracted from human brain, Ann Neurol 22 (3) (1987).

18. Dacey MF, Evaluation of the Poisson Approximation to measures of the random pattern in the square, Geographical Analysis 7 (1975) 351-367.

19. Clark PJ, Grouping in spatial distributions, Science 123 (1956) 373-374.

20. Clark PJ, Evans FC, Distance to nearest neighbour as a measure of spatial relationships in populations, Ecology 35 (1954) 445-453.

21. Moore PG, Spacing in plant populations, Ecology 35 (1954) 222-227.
22. Rogers A, Quadrat analysis of urban dispertion: 1. Theoretical techniques, Environment and Planning 1 (1975) 47-80.

23. Skellam JG, Studies in statistical ecology I. Spatial pattern, Biometrika 39 (1952) 346-462.

24. Laemmli UK, Cleavage of structural proteins during the assembly of the head of bacteriophage T4, Nature 227 (1970) 68-685.

25. Bradford MM, A rapid and sensitive method for the quantitation of microgram quantities of protein utilizing the principle of protein-dye binding, Anal Biochem 72 (1976) 248-254.

26. Towbin H, Staehlin T, Gordon J, Electrophoretic transfer of proteins from polyacrylamide gels to nitrocellulose sheets. Procedure and some applications, Proc Natl Acad Sci USA 76 (1979) 4350-4354.

27. Hara M, Microscopic globular bodies in the human brain, J Neuropathol Exp Neurol 45 (1986) 169-178.

28. George DH, Munoz DG, McConnell T, Dense microspheres in the human hippocampus, Acta Neuropathol (Berl) 86 (1983) 86-89.

29. Price JL, Davis PB, Morris JC, White DL, The distribution of tangles, plaques, and related immunohistochemical markers in healthy aging and Alzheimer's disease, Neurobiology of Aging 12 (1991) 295-312.

30. Ikeda S, Allsop D, Glenner GG, A study of the morphology and distribution of amyloid $\beta$ protein immunoreactive plaque and related lesions in the brains of Alzheimer's disease and adult Down's Syndrome, Alz Dis Related Disorders 317 (1989) 313-323.

31. Caramelli P, Robitaille Y, Cholette A-L, et al, Clinicopathological study in Alzheimer's disease: senile plaques correlate with profiles of cognitive impairment, in Alzheimer's Disease Biology, Diagnosis, and Therapeutics, Iqbal K, Winblad B, et al (eds) (Wiley, 1997) 267-274.

32. Jellinger K, Lassmann H, Fischer P, Danielczyk W, Validation of Diagnostic Criteria for Alzheimer's disease, in Alzheimer's Disease: Basic Mechanisms, Diagnosis and Therapeutic Strategies, Iqbal K, McLachlan DRC, Winblad B, Wisniewski H (eds) (Wiley, 1991) 75-89.

33. Tomlinson BE, Blessed G, Roth M, Observations on the brains of demented old people, J Neurol Sci 11 (1970) 205-242.

34. Davous P, Fallet-Bianco C, Roudier M, Lamour Y, A comparison of “pure” Alzheimer's disease and Alzheimer's disease plus vascular lesions (mixed dementia) in the elderly, in Basic Clinical and Therapeutic Aspects of Alzheimer's and 
Parkinson's Diseases, Vol 1 (Plenium Press, 1990) 357-361.

35. Armstrong RA, Myers D, Smith CUM, Alzheimer's disease: size class frequency distribution of senile plaques, do they indicate when a brain tissue was affected, Neuroscience Lett 127 (1991) 223-226.

36. Glenner GG, Wong CW, Alzheimer's disease: initial report of the purification and characterization of a novel cerebrovascular amyloid protein, Biochem Biophys Res Commun 120 (1984) 885-890.

37. Kimura T, Hisano T, Yoshida H, Ueda K, Miyakawa T, Classification of senile plaques by three-dimensional analysis, Jap J Psychiatr Neurol 47 (1993) 657-660.

38. Masters CL, Simms G, Weinman NA, Multhamp G, McDonald BI, Beyreuther I, Amyloid plaque core protein in Alzheimer's disease and Down syndrome, Proc Nat Acad Sci USA 82 (1985) 4245-4249.

39. Selkoe DJ, Abraham CR, Podlisny MB, Duffy LK, Isolation of low molecular weight proteins from amyloid plaque fibers in Alzheimer's disease, J Neurochem 146 (1986) 1820-1834.

40. Kang J, Lemaire H, Unterbeck A, et al, The precursor of Alzheimer's disease amyloid A4 protein resembles a cell-surface receptor, Nature 325 (1987) 733-736.

41. Van Nostrand WE, Wagner SL, Suzuki M, et al, Protease nexin-II, a potent anti-chymotrypsin, shows identity to amyloid beta protein precursor, Nature 341 (1989) 546-549.

42. Oltersdorf T, Fritz LC, Schenk DB, Lieberburg I, Johnson-Wood KL, Beattie EC, Ward PJ, Blacher RW, Dovey HF, and Sinha S, The secreted form of the Alzheimer's amyloid precursor protein with the Kunitz domain is protease nexin-II, Nature 341 (1989) 144-147.
43. Van Nostrand WE, Wagner SL, Suzuki M, Choi $\mathrm{BH}$, Farrow JS, Geddes JW, Cotman CW, Cunningham DD, Protease nexin-II, a potent antichymotrypsin, shows identity to amyloid $\beta$ protein precursor, Nature 341 (1989) 546-549.

44. Iversen LL, Mortishire-Smith RJ, Pollack SJ, Shearman MS, The toxicity in vitro of $\beta$-amyloid protein, Biochem J 311 (1995) 1-16.

45. Selkoe D, Alzheimer's disease: A central role for amyloid, J Neuropathol Exp Neurol 53 (1994) 438-447.

46. Underwood EE, de Wit R, Moore GA (eds), Fourth International Congress for Stereology, (National Bureau of Standards publication, 1976) 431.

47. Rose PE, Improved tables for the evaluation of sphere size distributions including the effect of section thickness, J Microsc 118 (1970) 135-141.

48. Harper JD, Wang S, Lieber CM, Lansbury PT, Observation of metastable A $\beta$ amyloid protofibrils by atomic force microscopy, Chem Biol 4 (1997) 119-125.

49. Wisniewski H, Johnson AB, Raine CS, Kay WJ, Terry RD, Senile plaques and cerebral amyloidosis in aged dogs. A histochemical and ultrastructural study, Lab Invest 23 (1970) 287296.

50. Wisniewski HM, Ghetti B, Terry RD, Neuritic (senile) plaques and filamentous changes in aged rhesus monkeys, J Neuropathol Exp Neurol 32 (1973) 566-584.

51. Selkoe DJ, Bell DS, Podlisny MB, Price DL, Cork LC, Conservation of brain amyloid proteins in aged mammals and humans with Alzheimer's disease, Science 235 (1987) 873-877.

52. Van Dumen SG, et al, Proc Nat Acad Sci USA 84 (1987) 5991. 